\title{
Catalytic deoxygenation of vapors obtained from ablative fast pyrolysis of wheat straw
} using mesoporous HZSM-5

Eschenbacher, Andreas; Jensen, Peter Arendt; Henriksen, Ulrik Birk; Ahrenfeldt, Jesper; Ndoni, Sokol; Li, Chengxin; Duus, Jens Øllgaard; Mentzel, Uffe Vie; Jensen, Anker Degn

\section{Published in:}

Fuel Processing Technology

Link to article, DOI:

10.1016/j.fuproc.2019.106119

Publication date:

2019

Document Version

Peer reviewed version

Link back to DTU Orbit

Citation (APA):

Eschenbacher, A., Jensen, P. A., Henriksen, U. B., Ahrenfeldt, J., Ndoni, S., Li, C., Duus, J. Ø., Mentzel, U. V., \& Jensen, A. D. (2019). Catalytic deoxygenation of vapors obtained from ablative fast pyrolysis of wheat straw using mesoporous HZSM-5. Fuel Processing Technology, 194, [106119].

https://doi.org/10.1016/j.fuproc.2019.106119

\section{General rights}

Copyright and moral rights for the publications made accessible in the public portal are retained by the authors and/or other copyright owners and it is a condition of accessing publications that users recognise and abide by the legal requirements associated with these rights.

- Users may download and print one copy of any publication from the public portal for the purpose of private study or research.

- You may not further distribute the material or use it for any profit-making activity or commercial gain

- You may freely distribute the URL identifying the publication in the public portal 


\title{
Catalytic Deoxygenation of Vapors obtained from Ablative Fast Pyrolysis of Wheat Straw Using Mesoporous HZSM-5
}

\author{
Andreas Eschenbacher ${ }^{[\mathrm{a}]}$, Peter Arendt Jensen ${ }^{[\mathrm{a}]}$, Ulrik Birk Henriksen ${ }^{[\mathrm{b}]}$, Jesper Ahrenfeldt ${ }^{[\mathrm{b}]}$, Sokol Ndoni ${ }^{[\mathrm{c}]}$, \\ Chengxin Li ${ }^{[\mathrm{d}]}$, Jens Øllgaard Duus ${ }^{[\mathrm{d}]}$, Uffe Vie Mentzel ${ }^{[\mathrm{e}]}$, and Anker Degn Jensen*[a]

\begin{abstract}
[a] DTU Chemical Engineering, Technical University of Denmark, Søltofts Plads 229, 2800 Kgs. Lyngby, Denmark
${ }^{[b]}$ DTU Chemical Engineering, Technical University of Denmark, Frederiksborgvej 399, 4000 Risø, Denmark

[d] DTU Chemistry, Technical University of Denmark, Kemitorvet 207, 2800 Kgs. Lyngby, Denmark

${ }^{[e]}$ Haldor Topsøe A/S, Haldor Topsøes Allé 1, 2800 Kgs. Lyngby, Denmark
\end{abstract} \\ ${ }^{[c]}$ DTU Nanotech, Technical University of Denmark, Produktionstorvet 423, 2800 Kgs. Lyngby, Denmark
}

\begin{abstract}
Steam treated HZSM-5 with different $\mathrm{Si} / \mathrm{Al}$ ratios were tested as catalysts for the upgrading of wheat straw pyrolysis vapors and their performance was compared to hierarchical counterparts, which were prepared by desilication followed by acid washing. Pyrolysis vapors were generated in an ablative system, hot gas filtered, and upgraded in an ex-situ catalyst bed to remove oxygen functionalities and reduce the oils' total acid number (TAN). Besides elemental analysis and TAN, the collected liquids were analyzed for water, chemical composition by gas chromatography mass spectrometry with flame ionization detection (GC-MS/FID), size exclusion chromatography (SEC), thermogravimetric analysis (TGA), and selectively by ${ }^{1} \mathrm{H}$ nuclear magnetic resonance (NMR), ${ }^{13} \mathrm{C} \mathrm{NMR}$, and two-dimensional heteronuclear single-quantum correlation (2D HSQC) NMR. Hierarchical and conventional catalysts were analyzed with X-ray fluorescence (XRF), ammonia temperatureprogrammed desorption ( $\mathrm{NH}_{3}$-TPD) and ethylamine TPD, $\mathrm{N}_{2}$ and Ar-physisorption, transmission electron microscopy (TEM) and X-ray diffraction (XRD) to investigate changes induced by the desilication process. In addition, samples were analyzed after several reaction and regeneration cycles to investigate catalyst stability. The hierarchical samples showed an increased coking propensity compared to their parent version. The introduction of mesopores after desilication of HZSM-5 with molar Si/Al ratios of 29 and 39 lead to prolonged activity in deoxygenation and improved carbon recovery in the collected oil fractions compared to the parent counterparts. The results indicate that mild deoxygenation may be a viable way of pretreating pyrolysis oil before co-processing with fossil oil in refineries.
\end{abstract}

Keywords: zeolites; biomass; heterogeneous catalysis; desilication; fast pyrolysis

*E-mail:aj@kt.dtu.dk

\section{Introduction}

Biofuels are instrumental to increase the share of renewables in the transport sector and fast pyrolysis is a simple and robust, technology to convert biomass feedstocks into liquid bio-oil[1-3]. Fast pyrolysis requires short residence times $(<2 \mathrm{~s})$, fast heating rates $\left(\sim 500{ }^{\circ} \mathrm{C} / \mathrm{s}\right)$, moderate to high temperatures $\left(400-700{ }^{\circ} \mathrm{C}\right)$, and low pressures $(<5 \mathrm{~atm})$ in order to obtain a high oil yield[1]. The obtained oils contain up to 400 different compounds including acids, esters, alcohols, ketones, aldehydes, sugars, furans, phenols, guaiacols, and syringols[4]. In order 
to (co-)process bio-oil at oil refineries, reduction of the oil's oxygen content and acidity is required[5]. Deoxygenation can be obtained by direct upgrading of the pyrolysis vapors under atmospheric conditions over solid acid catalysts, which makes catalytic fast pyrolysis (CFP) interesting compared to high pressure hydrotreating of raw pyrolysis oil[6]. HZSM-5 with a molar Si/Al range of 11-40 is considered most suitable for production of aromatics and gasoline range products when upgrading biomass derived pyrolysis vapors as the shape selective micropores improve the selectivity to aromatics and limit coke formation[7,8]. A Si/Al of 15 has been found optimal for high aromatic yields [9-11], although at the cost of low overall oil yield. The selectivity to aromatics rapidly decreases with increasing amount of biomass fed due to the rapid coking. The coke formation has been attributed to polymerization of small oxygenates on the zeolite's external surface, potentially causing pore blockage[12]. Catalyst activity can be regained by oxidative regeneration.

Hierarchical zeolites possess both micro and mesoporosity, with the mesopores being connected to the micropores and to the external surface of the particles, thereby allowing reactants to access the active centers (mostly located inside the micropores) faster. Examples of the benefits of hierarchical zeolites for several reaction types including methanol-to-hydrocarbon and aromatization reactions can be found e.g. in references [13-16]. The primary pyrolysis vapors contain bulky oxygenates such as lignin derived phenolic oligomers, which are too large to enter into the zeolite micropores. In order to reduce mass transfer limitations of conventional HZSM-5, additional mesoporosity may extend the upgrading reactions to bulkier molecules. The development of mesoporosity in HZSM-5 zeolite in an alkaline medium has been extensively described by Groen et al. for an optimal molar $\mathrm{Si} / \mathrm{Al}$ ratio of 25-50[17,18]. By using higher concentrated $\mathrm{NaOH}$ solutions, also HZSM-5 with lower $\mathrm{Si} / \mathrm{Al}$ ratios can be desilicated and acid washing with dilute $\mathrm{HCl}$ solution after the desilication increased the accessible micropore volume ( $\left.V_{\text {micro }}\right)$ due to removal of $\mathrm{Al}$ debris blocking the pore mouth entries [19].

Previous studies[20-23] using small scale batch pyrolyzers and a variety of biomasses as feed generally found that using mesoporous HZSM-5 lead to higher yield of monoaromatics while the influence on coke yield and gas was not always investigated or reported differently (see Table S1, supplementary information (SI)). While improvements in the catalytic performance were reported for mesoporous HZSM-5, the yields of oil and water and important oil/vapor properties like acidity and oxygen content were not disclosed.

Only few studies upgraded biomass derived fast pyrolysis vapors over mesoporous HZSM-5 at scales that allowed collection of liquid product. Park et al. [24] pyrolyzed $5 \mathrm{~g}$ woody biomass followed by upgrading of pyrolysis vapors over a fixed bed of $0.5 \mathrm{~g}$ mesoporous HZSM- 5 catalyst. The oil yield decreased and gas and coke yields increased over the mesoporous zeolite, but the deoxygenation and aromatization activity increased compared to the parent version. Park et al. [25] tested mesoporous HZSM-5 for the upgrading of miscanthus pyrolysis vapors and found that an improved activity in deoxygenation for the hierarchical HZSM-5 was accompanied by an increase in polyaromatics $(\mathrm{PAH})$ and coke. The organic liquid yield decreased from $35.7 \mathrm{wt}-$ $\%$ without catalyst to 21.5 and $20.4 \mathrm{wt}-\%$ using the parent and meso-HZSM-5, respectively. Using a bench-scale fixed bed tubular reactor, Asadieraghi et al. [26] evaluated the effect of added mesoporosity on the yield and composition of oil obtained at a cumulative biomass-to-catalyst ratios $(\mathrm{B}: \mathrm{C})=10$ from palm kernel shell. Compared to the parent HZSM-5, the bio-oil from meso-HZSM-5 showed lower concentrations of small oxygenates and higher concentration of aromatics, which was attributed to higher activity in aldol condensation and aromatization reactions. Jia et al.[27] monitored the change in vapor product distribution as function of 
increasing B:C ratio using an on-line mass spectrometer. Wood particles were stepwise injected into a micro fluidized bed reactor $\left(500^{\circ} \mathrm{C}\right)$ containing $5 \mathrm{~g}$ of HZSM-5 $(\mathrm{Si} / \mathrm{Al}=45)$ or its desilicated (mesoporous) version. Compared to the parent HZSM-5, the hierarchical sample formed 31\% more coke at B:C $=1.7$. Higher yields and a broader distribution of mono- and di-aromatics was obtained over the hierarchical HZSM-5 while the yield of olefins and aromatic hydrocarbons decreased faster for the parent zeolite due to a faster deactivation.

For a detailed comparison, both the oxygen content and yields of the oils obtained from the parent and mesoporous HZSM-5 should be considered - information which was not always fully provided in above studies $[25,26,28]$. In addition, results reported for batch type and/or in-situ catalyst configurations where the biomass is mixed with the catalyst may affect the product distribution differently compared to continuous feeding of vapors to an ex-situ located catalyst bed. The majority of the above mentioned studies were operated to a single cumulative $\mathrm{B}: \mathrm{C}$ ratio, at which the product distribution was compared. Thus, the literature lacks information about the changes in oil yield and quality with increasing time-on-stream for mesoporous HZSM-5. Furthermore, two important aspects were often overlooked in the catalyst preparation. Firstly, for the studies that applied desilication [20,21,23,26,29-31], not only the $\mathrm{NaOH}$ concentrations but also other treatment conditions like time and temperature varied. An acid wash treatment was only conducted in few cases[31-33], using 0.1M HCl. Without the acid wash, the access to micropores may have been partly blocked and the benefit of mesopore introduction may have been compromised. Secondly, the mentioned studies reported the performance for mesoporous HZSM5 that had not previously been exposed to hydrothermal conditions, which ignores the possibility that the stability of the zeolite may have decreased by the introduction of mesopores. The loss in acidity of the zeolite due to dealumination under hydrothermal affects the product distribution. The deactivation in the above studies was therefore a combination of irreversible deactivation by steam caused by dealumination and reversible deactivation by coke deposition.

A large body of scientific work related to catalytic fast pyrolysis (CFP) covers wood as feedstock due to its low ash content and thus higher oil yield [3,34-37]. The potential of wheat straw as a renewable source of fuels and chemicals via fast pyrolysis has been recognized by several researchers[38-44]. To the best of the authors knowledge, the closest available work reporting direct deoxygenation of straw pyrolysis vapors using HZSM-5 and specifically mesoporous HZSM-5 was reported by Hernando et al.[45], using Al-rich hierarchical HZSM-5 $(\mathrm{Si} / \mathrm{Al}=12)$ for a batch-type conversion of $4 \mathrm{~g}$ of acid-washed wheat straw at a biomass-to-catalyst $(\mathrm{w} / \mathrm{w})$ ratio (B:C) of 1.4 and 2.5 in a downdraft fixed-bed reactor with two separated zones. Unfortunately, the parent Al-rich HZSM-5 was not included for comparison.

The ambiguous results reported in literature warrant further research in order to clarify if introducing auxiliary mesopores decreases the rate of deactivation and increases the tolerance towards deactivation by coke deposition during upgrading of biomass derived fast pyrolysis vapors. This is important as it would allow operating to higher cumulative $\mathrm{B}: \mathrm{C}$ ratios before crossing a certain threshold of minimum oil quality. With this work we addressed the research questions i) What yields of deoxygenated pyrolysis oil can be obtained from ex-situ catalytic straw fast pyrolysis over conventional and mesoporous HZSM-5, ii) Can the oil yield be increased by the introduction of mesopores for a similar degree of deoxygenation, and iii) Does mesoporous HZSM-5 retain activity for a longer time compared to its original counterpart when evaluated at similar original zeolite mass? We use desilication with $\mathrm{NaOH}$ to generate mesopores followed by a mild acid wash to remove Al debris potentially blocking pore 
entries [19]. The samples were initially steam treated to obtain (partially) equilibrated samples, thereby minimizing deactivation by dealumination [46] and allowing to study deactivation only by coking. Furthermore, instead of targeting the yield of monoaromatics as most previous studies, we focused on the carbon recovery of mildly deoxygenated and stabilized oil for its further processing in an oil refinery. To this end, we performed the ex-situ upgrading of continuously fed pyrolysis vapors over various conventional and mesoporous HZSM-5 in bench-scale and correlated the change in product distribution towards increasing cumulative biomass-to-catalyst ratios with the oil's quality.

\section{Material and Methods}

Pyrolysis. The characteristics of the feedstock (wheat straw) and the experimental set-up of an ablative fast pyrolysis unit coupled to ex-situ deoxygenation of the hot vapors were described recently [47]. Scheme S1 shows a diagram of the reaction system. Straw was fed at $\sim 200 \mathrm{~g} / \mathrm{h}$ to the pyrolysis reactor, which was operated at 530 ${ }^{\circ} \mathrm{C}$. The nitrogen carrier gas $(8 \mathrm{Nl} / \mathrm{min})$ was preheated to $450{ }^{\circ} \mathrm{C}$. Char separation was achieved by cyclones $(450$ $\left.{ }^{\circ} \mathrm{C}\right)$ and hot gas filtration using a ceramic filter candle $\left(350{ }^{\circ} \mathrm{C}\right)$ upstream the ex-situ located catalytic fixed bed operated at $500{ }^{\circ} \mathrm{C}$. This temperature was chosen as a compromise between deoxygenation activity and excessive coke and gas formation. Vapors were condensed in three stages: At $4{ }^{\circ} \mathrm{C}$, a series of metal impingers was used, followed by an electrostatic precipitator (ESP) operated at room temperature, and a series of glass impingers cooled to $-60^{\circ} \mathrm{C}$. The total liquid product (excluding the moisture introduced from biomass) is defined as the sum of reaction water, the organics contained in the three oil fractions (OF), and the organics contained in the two aqueous fractions (WF). The sum of the water-free organic content obtained in the OF and WF fractions will be referred to as organic liquid (OL). Non-condensable gases (NCG) were analyzed using NDIR and GC-TCD/FID.

Catalyst Preparation. The parent HZSM-5 zeolites with $\mathrm{Si} / \mathrm{Al}=16,28$, and 39 (determined by XRF) were obtained from Zeolyst Int. and the product codes CBV 3024E, CBV 5524G, and CBV 8014 are abbreviated with CBV30, CBV55 and CBV80 in the following. A screening study of desilication conditions for the Al-rich CBV30 was conducted prior to preparation of a larger batch of mesoporous material as is further elaborated in the supporting information (SI), section S1. The desilication was performed with an electrically heated and stirred reactor system (see Fig. S1, SI). Based on the results of the screening study, mesoporous CBV30 was prepared by desilication of $300 \mathrm{~g}$ zeolite with $0.6 \mathrm{M} \mathrm{NaOH}$ for $30 \mathrm{~min}$ at $65^{\circ} \mathrm{C}$ and a liquid to solid ratio (L/S) of 50, followed by acid washing with $0.06 \mathrm{M} \mathrm{HCl}$ solution for $6 \mathrm{~h}$ at $65^{\circ} \mathrm{C}$. The solid yield amounted to $50 \%$, which can be attributed to the extensive mesopore formation and the high L/S ratio employed. Desilication of CBV55 and CBV80 was performed according to the procedure reported by Groen et al. [48] and Verboekend et al. [19], using $0.2 \mathrm{M} \mathrm{NaOH}$ at $65^{\circ} \mathrm{C}$ for $30 \mathrm{~min}$ at $\mathrm{L} / \mathrm{S}=30$, followed by a mild acid wash with $0.02 \mathrm{M} \mathrm{HCl}$ to remove $\mathrm{Al}$ debris. In an attempt to limit extensive mesopore formation and increase the remaining solid yield after desilication of CBV80, an additional batch of mesoporous CBV80 was prepared using half the amount of leaching solution (L/S = 15). In addition, this batch was started from the calcined zeolite while for all others the desilication was performed using the ammonium form of the zeolite.

All hierarchical materials were ion-exchanged with $1 \mathrm{M} \mathrm{NH} \mathrm{NNO}_{3}$ at $80{ }^{\circ} \mathrm{C}$ for $24 \mathrm{~h}$, dried overnight and subsequently calcined at $550{ }^{\circ} \mathrm{C}\left(\operatorname{ramp~} 3{ }^{\circ} \mathrm{C} / \mathrm{min}\right)$ for $5 \mathrm{~h}$ under dry air flow. The parent zeolite samples were 
received in the ammonium form and calcined under the same conditions. All catalysts were steamed prior to their first use for vapor upgrading by injecting water into a preheated nitrogen stream $(4 \mathrm{Nl} / \mathrm{min})$ and passing the steam ( $\sim 30$ vol-\%) over the zeolite bed kept at $500{ }^{\circ} \mathrm{C}$ for $5 \mathrm{~h}$ under atmospheric pressure conditions.

Vapor Upgrading. The experiments were stopped once a certain mass ratio of dry and ash-free (daf) wheat straw compared to catalyst was fed (indicated by B:C). Table 1 numbers the experimental runs and summarizes the operating conditions. Two externally heated reactors of different size were used in the experiments. A larger reactor (ID $=67 \mathrm{~mm}$, length $=250 \mathrm{~mm}$ ) was used at low $\mathrm{B}: \mathrm{C}$ ratios up to $\mathrm{B}: \mathrm{C} \sim 10$, filled with $\sim 300 \mathrm{ml}$ of catalyst volume (93-151 g) which corresponded to a weight hourly space velocity (WHSV) in the range of 1.2-2.2 $\mathrm{g}_{\text {biomass }} /\left(\mathrm{g}_{\text {catalyst }} \cdot \mathrm{h}\right)$, with the exception of CBV55 (WHSV $=0.5 \mathrm{~g}_{\text {biomass }} /\left(\mathrm{g}_{\text {catalyst }} \cdot \mathrm{h}\right)$ ) for which results were reported previously[47]. In order to reach high $\mathrm{B}: \mathrm{C}$ ratios, it was necessary to run with lower catalyst mass and tests operated to higher $\mathrm{B}: \mathrm{C}$ ratios up to $\mathrm{B}: \mathrm{C} \sim 22$ were performed using a smaller reactor (ID $=20 \mathrm{~mm}$, length $=190$ $\mathrm{mm}$ ) with 15-26 g catalyst, corresponding to a WHSV range of 6.1-10.6 $\mathrm{g}_{\text {biomass }} /\left(\mathrm{g}_{\text {catalyst }} \mathrm{h}\right)$. The WHSV of the lower catalyst loadings was 4.3 to 5.3 times higher compared to using the larger mass of catalyst, with the exception of CBV55 (15 times higher WHSV) as reported earlier [47]. For both reactor sizes, quartz wool and perforated distribution plates were placed between the catalyst bed and gas inlet/outlet pipes in order to ensure plug flow behavior and avoid channeling or dead pockets. Due to the differences in WHSV, the performance of the catalysts should be compared for each reactor size, and not across the two reactor scales. The effect of catalyst loading at similar B:C ratio is visible by comparing experiment Z502 with Z503, experiment MZ503 with MZ504, and experiment MZ802 with MZ803. Despite differences in the biomass feeding rate, the vapor contact time, predominantly determined by the carrier gas flow rate, was comparable for all runs conducted with $\sim 60$ or $\sim 300$ $\mathrm{ml}$ catalyst volume, respectively. For each reactor size, the same volume of catalyst was used since this is the most relevant way of comparing catalysts from a practical point of view. This further seems a fair way of comparing parent and desilicated catalysts since the volume of a certain mass of parent zeolite is roughly the same as its desilicated version. Fig. S2 shows examples of temperature profiles for the two different reactor scales and steamed versions of CBV30 and CBV80. Upon contact of the vapors with the fresh or regenerated catalyst bed, the bed temperature initially increased by $\sim 15{ }^{\circ} \mathrm{C}-30{ }^{\circ} \mathrm{C}$ due to exothermic reactions. Note also that the temperature rise was lower for the less active CBV80 compared to CBV30.

The yield of non-condensable gases may be under-represented for the shortest run-times (Z503 and MZ803) due to a gas-sampling interval of $>10 \mathrm{~min}$ on the GC. Passing the hot pyrolysis vapors over $60 \mathrm{ml}(95 \mathrm{~g})$ of $\mathrm{SiC}$ produced a "thermal" reference oil, and from repeated experiments over the $\mathrm{SiC}$ bed the experimental uncertainty (in terms of \pm 2 standard deviations) for the yields of gas, organic liquid, reaction water, and char was estimated to $2.1 \mathrm{wt}-\%, 0.4 \mathrm{wt}-\%, 0.8 \mathrm{wt}-\%$ and $3.8 \mathrm{wt}-\%$, respectively. The mass balance closures were in the range 90 $101 \%$.

For oxidative regeneration of the catalysts, nitrogen was mixed with air to obtain $\sim 2$ vol- $\% \mathrm{O}_{2}$ (total flowrate $2 \mathrm{Nl} / \mathrm{min}$ ) and the temperature was ramped from $250{ }^{\circ} \mathrm{C}$ to $\sim 550{ }^{\circ} \mathrm{C}$ at $1{ }^{\circ} \mathrm{C} / \mathrm{min}$. The final temperature was held for several hours and the nitrogen was stepwise replaced by air until no more $\mathrm{CO}$ and $\mathrm{CO}_{2}$ was measured in the effluent gas stream.

Catalyst and Oil Characterization. The majority of the methodology for catalyst and oil characterization has been outlined in detail in our previous work [47]. In addition to the previous reported methodology, TEM images 
were acquired using a Tecnai T20 G2 (acceleration voltage of $200 \mathrm{kV}$ ). Samples were prepared by dispersion of the sample in methanol in an ultrasonic bath, after which drops of the dispersion were placed on a copper grid containing a lacey carbon film and dried over-night. A description of the methodology for characterization of the catalyst's total acidity and acid strength distribution using $\mathrm{NH}_{3}-\mathrm{TPD}$ as well as the quantification of the Brønsted acidity by TPD of Ethylamine is provided under section S2, SI. It is noted that the experiments Z501 to Z504 were part of a recently submitted work, which focused on the change in oil quality at continued vapor upgrading over an increasingly coked CBV55 [47]. Since the focus of this work lies on the performance comparison of mesoporous HZSM-5 with their parent versions for a range of different $\mathrm{Si} / \mathrm{Al}$ ratios, we will refer to the results obtained with the parent CBV55 for comparison.

Table 1. Process conditions of the test series for comparison of CBV30, CBV55, and CBV80 with its respective mesoporous version. All zeolitic catalysts were steamed (suffix 'st') prior to the first reaction cycle and the suffixes ' $u$ ', and ' $r$ ' to the catalyst designation indicate the number of previous vapor upgrading and regeneration procedures. ' $\mathrm{L} / \mathrm{S}$ ' refers to the liquidto-solid ratio applied for desilication.

\begin{tabular}{|c|c|c|c|c|}
\hline $\begin{array}{l}\text { Experiment } \\
\text { number }\end{array}$ & Catalyst & $\begin{array}{c}\text { Amount } \\
\text { catalyst }[\mathrm{g}]\end{array}$ & $\begin{array}{c}\text { Biomass (daf) } \\
\text { feeding rate } \\
{[\mathrm{g} / \mathrm{min}]}\end{array}$ & $\begin{array}{l}\text { cumulative } \\
\text { biomass-to-catalyst } \\
\text { ratio (cum. B:C) }\end{array}$ \\
\hline- & $\mathrm{SiC}$ & 95 & 2.7 & 11 \\
\hline Z301 & CBV30-st & 143 & 4.1 & 1.4 \\
\hline Z302 & CBV30-st- $\mathrm{u}^{2}-\mathrm{r}^{2}$ & 143 & 3.3 & 3.6 \\
\hline Z303 & CBV30-st-u-r & 143 & 3.3 & 6.1 \\
\hline Z304 & CBV30-st & 26 & 3.3 & 10.7 \\
\hline MZ301 & mesoCBV30-st & 93 & 3.4 & 2.4 \\
\hline MZ302 & mesoCBV30-st-u-r & 93 & 3.3 & 6.2 \\
\hline MZ303 & mesoCBV30-st- $u^{4}-r^{4}$ & 20 & 3.1 & 9.2 \\
\hline Z501 & CBV55-st & 151 & 1.4 & 1.7 \\
\hline Z502 & CBV55-st-u-r & 151 & 1.1 & 6.2 \\
\hline Z503 & CBV55-st- $\mathrm{u}^{3}-\mathrm{r}^{3}$ & 15 & 2.1 & 6.5 \\
\hline Z504 & CBV55-st-u ${ }^{2}-r^{2}$ & 15 & 1.7 & 12.9 \\
\hline MZ501 & mesoCBV55-st-u-r & 100 & 3.2 & 2.5 \\
\hline MZ302 & mesoCBV55-st & 100 & 2.9 & 6.4 \\
\hline MZ503 & mesoCBV55-st-u ${ }^{2}-r^{2}$ & 100 & 3.2 & 9.6 \\
\hline MZ504 & mesoCBV55-st-u ${ }^{3}-r^{3}$ & 20 & 3.3 & 11.2 \\
\hline Z801 & CBV80-st-u-r & 140 & 3.2 & 2.8 \\
\hline Z802 & CBV80-st & 140 & 2.4 & 4.5 \\
\hline Z803 & CBV80-st- $\mathrm{u}^{2}-\mathrm{r}^{2}$ & 24 & 2.8 & 9.9 \\
\hline Z804 & CBV80-st & 24 & 2.1 & 17 \\
\hline MZ801 & mesoCBV80-st, L/S = 15 & 90 & 3.0 & 2.4 \\
\hline MZ802 & mesoCBV80-st-u-r, L/S = 15 & 90 & 3.6 & 8.3 \\
\hline MZ803 & mesoCBV80-st-u-r, L/S = 30 & 15 & 2.6 & 10 \\
\hline MZ804 & mesoCBV80-st, L/S = 30 & 15 & 2.7 & 21.8 \\
\hline
\end{tabular}

\section{Results}

\subsection{Physicochemical catalyst characterization}

The isotherms and pore size distributions obtained from argon and nitrogen physisorption are provided for both the parent and mesoporous zeolites as SI, Fig. S3-S8, and the physisorption data confirmed the formation of mesopores by the desilication. Acidity characterization by $\mathrm{NH}_{3}$-TPD was performed for the calcined zeolites, after 
their steam treatment, and after several reaction/regeneration cycles. Desorption profiles are provided as SI, Fig. S9-S13. The determination of the Brønsted acidity by TPD of Ethylamine was obtained by integration of the desorption peak of $\mathrm{NH}_{3}$ as reaction product at $\sim 420^{\circ} \mathrm{C}[49,50]$, and the desorption profiles are shown in Fig. S14S17 (SI). Table 2 includes both the overview of textural properties as well as the acidity characterization and the molar Si/Al ratio and the Na content determined by XRF analysis. The suffixes 'st', ' $u$ ', and ' $r$ ' to the catalyst designation indicate steaming, vapor upgrading, and regeneration, and the superscript number indicates the number of times the sample underwent the treatment in the sample's history. The two characteristic peaks desorbing at $\sim 220{ }^{\circ} \mathrm{C}$ and $\sim 430{ }^{\circ} \mathrm{C}$ of the acid strength distribution obtained by $\mathrm{NH}_{3}$-TPD were fitted (Gaussian) in order to obtain the distribution between strong (S) and weak (W) acidity. The Brønsted acidity of the hierarchical catalysts decreased further by $\sim 10 \%$ after several (2-4) reaction cycles. A more pronounced drop in Brønsted acidity by 38 and 26\% was observed for the parent steamed CBV30 and CBV55, respectively, while the decrease in Brønsted acidity for CBV80-st after three reaction-regeneration cycles was $10 \%$, indicating good stability.

For the parent CBV30, the steaming and repeated reaction-regeneration cycles decreased the microporous volume ( $\left.V_{\text {micro }}\right)$ from $0.21 \mathrm{cc} / \mathrm{g}$ to $0.17 \mathrm{cc} / \mathrm{g}$, while the mesoporous volume $\left(V_{\text {meso }}\right)$ increased from 0.09 to $0.11 \mathrm{cc} / \mathrm{g}$ (see Table 2 and Fig. S3). The steam pretreatment and continued exposure to hydrothermal conditions during the vapor upgrading and regeneration seem to have caused extended hydrolysis of Al-OH-Si bonds, leading to removal of instable domains and creating some voids in the mesoporous regime. The desilication decreased $V_{\text {micro }}$ from 0.21 to $0.15 \mathrm{cc} / \mathrm{g}$ and created $0.31 \mathrm{cc} / \mathrm{g}$ mesopores, about three times higher compared to the parent material. The physicochemical properties of the mesoCBV30 match very closely the hierarchical HZSM-5 investigated by Hernando et al. [45], who reported $\mathrm{Si} / \mathrm{Al}=12, V_{\text {micro }}=0.144 \mathrm{cc} / \mathrm{g}$ (probed by Ar-physisorption) and $V_{\text {total }}=0.584$ cc/g. CBV30 showed a ratio of strong-to-weak acid sites (S/W) of $\sim 1$, which was reduced to 0.8 after steaming and three reaction-regeneration cycles, indicating that strong acid sites were lost preferentially. For the mesoporous CBV30, a similar $\mathrm{S} / \mathrm{W}$ ratio resulted as for the parent CBV30, however, after steaming and few reaction-regeneration cycles its $\mathrm{S} / \mathrm{W}$ ratio decreased to $\sim 0.7$. The steamed mesoCBV30 largely preserved its acidity after four reaction-regeneration cycles, whereas the steamed CBV30 further lost acidity after three reaction-regeneration cycles to values below its mesoporous counterpart. The Brønsted acidity determined by TPD of Ethylamine was highest for the steamed CBV30 $\left(0.266 \mathrm{mmol} \mathrm{NH}_{3} / \mathrm{g}\right)$ compared to steamed CBV55 and CBV80; however, it decreased to $0.165 \mathrm{mmol} \mathrm{NH}_{3} / \mathrm{g}$ after three reaction-regeneration cycles (see Table 2). The mesoCBV30 retained more Brønsted acidity and strong acidity after repeated reaction-regeneration cycles compared to the parent $\mathrm{CBV} 30$.

For the parent CBV55, the steaming and repeated reaction-regeneration cycles decreased $V_{\text {micro }}$ from $0.22 \mathrm{cc} / \mathrm{g}$ to $0.2 \mathrm{cc} / \mathrm{g}$, while $V_{\text {meso }}$ slightly increased (see Table 2). The desilication decreased $V_{\text {micro }}$ slightly from 0.22 to $0.21 \mathrm{cc} / \mathrm{g}$, and increased $V_{\text {meso }}$ to $0.14 \mathrm{cc} / \mathrm{g}$. After steaming and repeated reaction-regeneration cycles, $V_{\text {meso }}$ further increased to $0.22 \mathrm{cc} / \mathrm{g}$, indicating the collapse of hydrothermally unstable framework sections. The desilication of CBV55 decreased the molar Si/Al ratio from 28 to 20, which correlated with an increase in acidity from 0.65 to $0.86 \mathrm{mmol} \mathrm{NH}_{3} / \mathrm{g}$. While both parent and mesoCBV55 lost about $50 \%$ of their initial acidity by the steaming and reaction-regeneration cycles, the mesoCBV55 maintained a higher acidity $(0.38 \mathrm{mmol} \mathrm{NH} / \mathrm{g})$ compared to the 
parent CBV55 $\left(0.3 \mathrm{mmol} \mathrm{NH}_{3} / \mathrm{g}\right)$. This agrees with a higher Brønsted acidity determined for mesoCBV55-st- $\mathrm{u}^{3}-$ $\mathrm{r}^{3}\left(0.152 \mathrm{mmol} \mathrm{NH}_{3} / \mathrm{g}\right)$ compared to CBV55-st- $\mathrm{u}^{4}-\mathrm{r}^{4}\left(0.118 \mathrm{mmol} \mathrm{NH}_{3} / \mathrm{g}\right)$.

The desilication increased the S/W acid site ratio for CBV55. However, after steaming and several reactionregeneration cycles lower $\mathrm{S} / \mathrm{W}$ ratios resulted for the mesoCBV55 compared to the parent CBV55. This illustrates that the physicochemical properties of mesoporous HZSM-5 may change upon exposure to hydrothermal conditions and that the results reported for the performance of mesoporous HZSM-5 that was not previously exposed to hydrothermal conditions may not be representative after long term use.

In order to investigate potential changes in crystallinity by the desilication, both the parent CBV55 and its desilicated version were analyzed by XRD. Fig. S7 (SI) shows a comparison of the XRD pattern which indicates that the MFI characteristic pattern was well preserved, both by the desilication and acid treatment as well as the steaming and repeated reaction-regeneration cycles. This is in agreement with others[51], who reported that desilication of CBV55 under similar conditions did not disturb the crystallinity of the resulting materials.

For desilication of CBV80, a decrease in the amount of leaching solution from $\mathrm{L} / \mathrm{S}=30$ to 15 reduced the created $V_{\text {meso }}$ from $0.19 \mathrm{cc} / \mathrm{g}$ to $0.17 \mathrm{cc} / \mathrm{g}$ and preserved more $V_{\text {micro. }}$. This way, extensive leaching was limited and a solid yield of $77 \mathrm{wt}-\%$ was obtained after leaching with $\mathrm{L} / \mathrm{S}=15$ compared to $62 \mathrm{wt}-\%$ remaining after leaching with $\mathrm{L} / \mathrm{S}=30$. Nevertheless, a considerable increase in total pore volume (from $0.24 \mathrm{cc} / \mathrm{g}$ for the parent sample to $0.37 \mathrm{cc} / \mathrm{g}$ ) and the introduction of mesopores $(0.06$ to $0.17 \mathrm{cc} / \mathrm{g})$ was achieved at $\mathrm{L} / \mathrm{S}=15$. Besides higher solid yields, the lower $\mathrm{L} / \mathrm{S}$ ratio produced less waste water, which is especially relevant for conducting the desilication in larger scale[52]. The pore size distribution according to the BJH analysis (Fig. S8, SI), shows that for L/S = 30 a small peak at $\sim 100 \AA$ pore width resulted and the broad pore size distribution extends into the range of macropores $(>500 \AA)$. A reduction in the amount of leaching solution $(\mathrm{L} / \mathrm{S}=15)$ yielded better-defined mesopores in the range of 50-600 $\AA$, centered at $\sim 220 \AA$. After steam treatment and two reaction-regeneration cycles, $V_{\text {meso }}$ increased by 6 and $26 \%$ for mesoCBV80 $(\mathrm{L} / \mathrm{S}=15)$ and mesoCBV80 $(\mathrm{L} / \mathrm{S}=30)$, respectively, indicating a better hydrothermal stability of the former, which may be attributed to its higher $\mathrm{Si}$ content ( $\mathrm{Si} / \mathrm{Al}=32$ vs. 23, respectively).

Amongst the parent zeolites the acidity of CBV80 was lowest $\left(0.52 \mathrm{mmol} \mathrm{NH}_{3} / \mathrm{g}\right)$, in line with its lower $\mathrm{Al}$ content. CBV80 showed a high $\mathrm{S} / \mathrm{W}$ ratio (1.2) which was maintained after steaming and decreased to $\mathrm{S} / \mathrm{W}=1.1$ after two reaction-regeneration cycles. The mesoCBV80 prepared by $\mathrm{L} / \mathrm{S}=30$ resulted in a higher acidity compared to the parent CBV80 after calcination, however, its acidity dropped considerably after steaming to 0.246 $\mathrm{mmol} \mathrm{NH}_{3} / \mathrm{g}$. The initial increase in acidity was also reflected by the clear reduction in molar Si/Al ratio of 39 to 23. For comparison, the mesoporous $\mathrm{CBV} 80$ prepared with $\mathrm{L} / \mathrm{S}=15$ had a lower acidity after calcination compared to the parent CBV80, however, it preserved $16 \%$ more acidity after steaming compared to mesoCBV80 $(\mathrm{L} / \mathrm{S}=30)$. The lower acidity of mesoCBV80 $(\mathrm{L} / \mathrm{S}=15)$ compared to mesoCBV80 $(\mathrm{L} / \mathrm{S}=30)$ can be attributed to the higher $\mathrm{Si} / \mathrm{Al}$ ratio ( 32 vs. 23 ) and the leaching of $\mathrm{Al}$ from the zeolite framework. The change in acidity by the desilication of CBV80 under similar conditions is in agreement with literature $[48,53,54]$. Comparing the steamed catalysts shows that the desilicated versions had $\sim 14 \%$ less strong acid sites compared to CBV80-st. For both CBV80 and its mesoporous versions, no considerable decrease in acidity was observed after their use for up to three reaction/regeneration cycles, indicating a high hydrothermal stability compared to more Al-rich samples at the given process conditions. 
The effect of severe coke deposition on the physiochemical properties was investigated for mesoCBV80 (L/S $=30$ ) after cumulative $\mathrm{B}: \mathrm{C}=22$. A reduction in $V_{\text {micro }}$ from 0.17 to $0.12 \mathrm{cc} / \mathrm{g}$ was observed, along with a reduction of $V_{\text {meso }}$ from 0.19 to $0.13 \mathrm{cc} / \mathrm{g}$ and a reduced BET surface area of $305 \mathrm{~m}^{2} / \mathrm{g}$. The coke that had accumulated on the catalyst completely poisoned the strong acid sites, while some weak acid sites remained of $\sim 0.05 \mathrm{mmol} \mathrm{NH}_{3} / \mathrm{g}$ (see Fig. S13).

The used catalysts CBV80-st- $u^{3}-r^{3}$, mesoCBV80 (L/S = 15)-st- $u^{2}-r^{2}$, and mesoCBV80 (L/S = 30)-st- $u^{2}-r^{2}$ were re-analyzed by XRF in order to verify that no transfer of alkaline ash material to the zeolite had occurred, which may result in poisoning of the zeolite's acid sites. No potassium or magnesium could be detected, however, a slightly elevated Ca content of $\sim 0.08$ wt- $\%$ was found for the two mesoporous CBV 80 while for the parent CBV80 the $\mathrm{Ca}$ content at the end of the test series was below the detection limit of $0.015 \mathrm{wt}-\%$. These results show that the filter upstream the reactor effectively removed any ash species from the vapor. 
Table 2. Physicochemical characterization of the parent HZSM-5 and their respective mesoporous materials. $V_{\text {micro }}$ and $S$ micro were determined by high-resolution low temperature Argon physisorption $(87 \mathrm{~K})$, while all other textural parameters were derived from nitrogen adsorption data. Acidity was determined by $\mathrm{NH}_{3}-\mathrm{TPD}$ and the weak (W) and strong (S) acidity was determined by Gaussian fitting of the two main desorption peaks at $\sim 220$ and $\sim 430{ }^{\circ} \mathrm{C}$, respectively. Brønsted acidity was quantified by TPD of Ethylamine. Si/Al ratio and Na content determined by XRF. The suffixes 'st', ' $u$ ', and ' $r$ ' to the catalyst designation indicate steaming, upgrading and regeneration procedures, with the superscript number indicating the number of times the sample underwent the treatment in the sample's history

\begin{tabular}{|c|c|c|c|c|c|c|c|c|c|c|c|}
\hline Sample & $\begin{array}{l}V_{\text {micro }} \\
{[\mathrm{cc} / \mathrm{g}]}\end{array}$ & $\begin{array}{c}S_{\text {micro }} \\
{\left[\mathrm{m}^{2} / \mathrm{g}\right]}\end{array}$ & $\begin{array}{l}V_{\text {meso }} \\
{[\mathrm{cc} / \mathrm{g}]}\end{array}$ & $\begin{array}{c}S_{\text {meso }} \\
{\left[\mathrm{m}^{2} / \mathrm{g}\right]}\end{array}$ & $\begin{array}{c}V_{\text {total }} \\
\text { at } \\
\mathrm{p} / \mathrm{p}_{0} \\
=0.99\end{array}$ & $\begin{array}{c}\mathrm{BET} \\
\left(\mathrm{N}_{2}\right) \\
{\left[\mathrm{m}^{2} / \mathrm{g}\right]}\end{array}$ & $\begin{array}{l}\text { Acidity } \\
{[\mathrm{mmol}} \\
\left.\mathrm{NH}_{3} / \mathrm{g}\right]\end{array}$ & $\begin{array}{l}\text { Ratio } \\
\mathrm{S} / \mathrm{W} \\
\text { acid } \\
\text { sites }\end{array}$ & $\begin{array}{c}\text { Brønsted } \\
\text { acidity } \\
{[\mathrm{mmol}} \\
\left.\mathrm{NH}_{3} / \mathrm{g}\right]\end{array}$ & $\begin{array}{l}\text { Molar } \\
\mathrm{Si} / \mathrm{Al}\end{array}$ & $\begin{array}{c}\mathrm{Na} \\
\text { content } \\
\text { [wt-\%] }\end{array}$ \\
\hline CBV30 & 0.207 & 1546 & 0.09 & 54 & 0.355 & 416 & 0.88 & 0.99 & n.a. & 16.4 & $<0.03$ \\
\hline CBV30-st & n.a. & n.a. & n.a. & n.a. & n.a. & n.a. & 0.51 & 0.80 & 0.266 & n.a. & n.a. \\
\hline CBV30-st-u $u^{3}-r^{3}$ & 0.168 & 1295 & 0.11 & 74 & 0.361 & 382 & 0.35 & 0.80 & 0.165 & 15.9 & $<0.03$ \\
\hline mesoCBV30 & 0.150 & 1166 & 0.31 & 103 & 0.543 & 421 & 0.71 & 1.03 & n.a. & n.a. & n.a. \\
\hline mesoCBV30-st & n.a. & n.a. & n.a. & n.a. & n.a. & n.a. & 0.44 & 0.68 & 0.186 & n.a. & n.a. \\
\hline mesoCBV30-st- $\mathrm{u}^{4}-\mathrm{r}^{4}$ & 0.134 & 1046 & 0.27 & 109 & 0.508 & 380 & 0.40 & 0.75 & 0.174 & 12.4 & 0.11 \\
\hline CBV55 & 0.22 & 1564 & 0.09 & 48 & 0.31 & 423 & 0.65 & 0.88 & 0.312 & 28.4 & $<0.025$ \\
\hline CBV55-st & 0.17 & 1297 & 0.11 & 92 & 0.29 & 399 & 0.36 & 0.78 & 0.160 & 27.8 & $<0.025$ \\
\hline CBV55-st-u $u^{4}-r^{4}$ & 0.20 & 1514 & 0.10 & 75 & 0.28 & 385 & 0.30 & 0.96 & 0.118 & 28.5 & $<0.025$ \\
\hline mesoCBV55 & 0.21 & 1438 & 0.14 & 77 & 0.42 & 422 & 0.86 & 1.13 & n.a. & 19.7 & 0.01 \\
\hline mesoCBV55-st & n.a. & n.a. & 0.23 & 101 & 0.49 & 392 & 0.42 & 0.53 & 0.169 & n.a. & n.a. \\
\hline mesoCBV55-st- $\mathrm{u}^{3}-\mathrm{r}^{3}$ & 0.17 & 1286 & 0.22 & 85 & 0.49 & 397 & 0.38 & 0.76 & 0.152 & n.a. & n.a. \\
\hline CBV80 & 0.20 & 1585 & 0.06 & 51 & 0.24 & 431 & 0.52 & 1.16 & n.a. & 39.3 & $<0.03$ \\
\hline CBV80-st & n.a. & n.a. & n.a. & n.a. & n.a. & n.a. & 0.34 & 1.22 & 0.150 & n.a. & n.a. \\
\hline CBV80-st- $\mathrm{u}^{2}-\mathrm{r}^{2}$ & 0.19 & 1427 & 0.08 & 70 & 0.30 & 419 & 0.39 & 1.09 & 0.135 & 38.3 & $<0.03$ \\
\hline mesoCBV80(L/S = 15) & 0.18 & 1372 & 0.17 & 78 & 0.37 & 414 & 0.42 & 1.04 & n.a. & n.a. & n.a. \\
\hline mesoCBV80(L/S = 15)-st & n.a. & n.a. & n.a. & n.a. & n.a. & n.a. & 0.29 & 0.69 & 0.120 & n.a. & n.a. \\
\hline mesoCBV80(L/S = 15)-st- $\mathrm{u}^{2}-\mathrm{r}^{2}$ & 0.18 & 1351 & 0.18 & 93 & 0.34 & 398 & 0.28 & 0.73 & 0.109 & 32.0 & 0.1 \\
\hline mesoCBV80(L/S = 30) & 0.17 & 1378 & 0.19 & 95 & 0.44 & 454 & 0.85 & 1.01 & n.a. & 22.9 & $<0.03$ \\
\hline mesoCBV80(L/S = 30)-st & n.a. & n.a. & n.a. & n.a. & n.a. & n.a. & 0.25 & 1.03 & n.a. & n.a. & n.a \\
\hline $\begin{array}{l}\text { mesoCBV80(L/S = 30)-st-u } \\
(\mathrm{B}: \mathrm{C}=22)\end{array}$ & 0.12 & 976 & 0.13 & 63 & 0.31 & 305 & 0.05 & 0.44 & n.a. & n.a. & n.a. \\
\hline $\operatorname{mesoCBV80}_{\mathrm{r}^{2}}(\mathrm{~L} / \mathrm{S}=30)-\mathrm{st}^{-\mathrm{u}^{2}-}$ & 0.17 & 1270 & 0.24 & 111 & 0.44 & 403 & 0.26 & 0.99 & 0.138 & 23.4 & 0.07 \\
\hline
\end{tabular}

TEM results for mesoporous CBV30 are shown in Fig. 1 a-b. Image analysis (Fig. S18) indicates welldistributed mesopores in the range of $4-10 \mathrm{~nm}$ pore width, in good agreement with the pore size distribution obtained by $\mathrm{N}_{2}$ and Ar characterization (Fig. S3-S6 and S8-S9). TEM images of the mesoporous CBV55 are shown in Figure 1c-d. TEM of CBV80 derived mesoporous samples confirm the development of mesopores for 
both $\mathrm{L} / \mathrm{S}=15$ and L/S = 30 (Figure 1e-f). For desilicated CBV55 and CBV80, not all crystals have been attacked uniformly and the creation of mesopores has happened in some instances preferentially at the crystal centers, leaving behind a rim of parent material without substantial mesoporosity. Nevertheless, most pores appear welldistributed and based on TEM images it is expected that the accessibility and utilization of the bulk crystal material will be improved by the perforation of the crystals with mesopores. The pore size distribution based on image analysis (Fig. S18) shows that for desilicated CBV55 and CBV80 materials the pore size distribution has become broader and extends to larger pores compared to desilicated CBV30. Using twice the amount of leaching solution $(\mathrm{L} / \mathrm{S}=30)$ for CBV80 resulted in a higher degree of crystal dissolution at their centers (Figure 1f), while some parts of the outer crystal volume still were less selectively attacked. Al-zoning [55,56] refers to an enriched Al concentration towards the outer crystal rim of the parent material and may explain why the rim was less selectively attacked since a higher framework $\mathrm{Al}$ content is more recalcitrant to $\mathrm{OH}^{-}$attack[57,58]. Both nearly intact and heavily leached crystals were observed in the work of Fodor et al.[59] for commercially available HZSM-5 crystals $(\mathrm{Si} / \mathrm{Al}=14)$, pointing to different dissolution rates of individual HZSM-5 crystals.
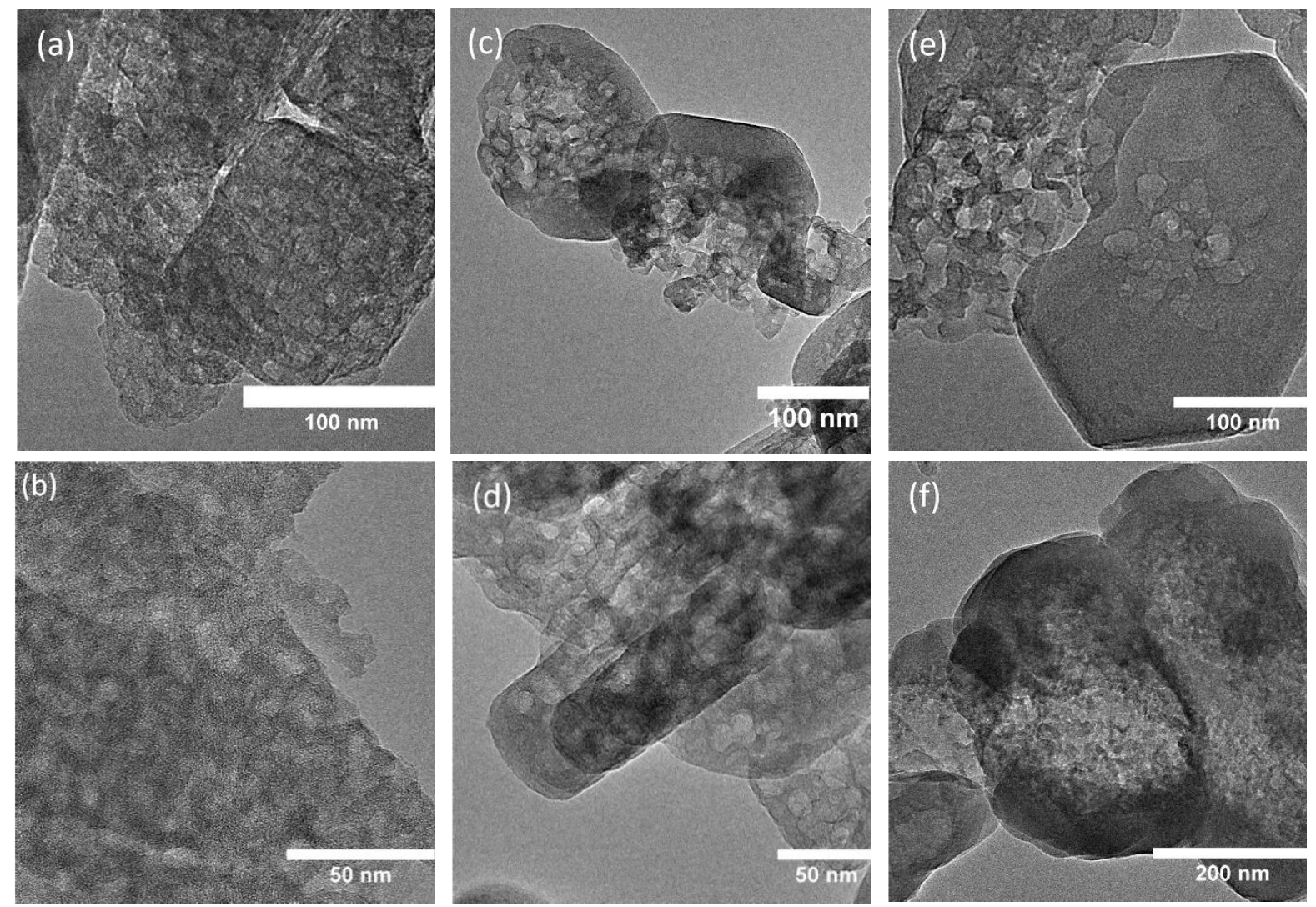

Figure 1. (a) and (b) show TEM images of mesoCBV30 prepared by leaching with $0.6 \mathrm{M} \mathrm{NaOH}, \mathrm{L} / \mathrm{S}=50,30 \mathrm{~min}$ at $65^{\circ} \mathrm{C}$, followed by acid wash with $0.06 \mathrm{M} \mathrm{HCl}, 6 \mathrm{~h}$ at $65^{\circ} \mathrm{C}$. (c) and (d) show TEM images of mesoCBV55 prepared by leaching with $0.2 \mathrm{M} \mathrm{NaOH}, \mathrm{L} / \mathrm{S}=30,30 \mathrm{~min}$ at $65^{\circ} \mathrm{C}$, followed by acid wash with $0.02 \mathrm{M} \mathrm{HCl}, 6 \mathrm{~h}$ at $65^{\circ} \mathrm{C}$. (e) and (f) show TEM images of mesoCBV80 prepared by leaching with $0.2 \mathrm{M} \mathrm{NaOH}, 30 \mathrm{~min}$ at $65^{\circ} \mathrm{C}$ and $\mathrm{L} / \mathrm{S}=15$ (e) or $\mathrm{L} / \mathrm{S}=30$ (f), respectively. Both mesoCBV80 materials underwent the same acid treatment as for mesoCBV55. 


\subsection{Product distribution}

Figure 2a-c shows the product distributions for CBV30, CBV55, CBV80, and their mesoporous versions, respectively. Yields are shown based on daf biomass fed; therefore, the 'reaction water' does not include the moisture introduced with the biomass and the organic liquid refers to the dry organics content collected as liquid product. For sake of clarity, the coke yield was multiplied by 10 .

Results for SiC (grey bars) are included as non-catalytic reference. Char yields are not shown for sake of brevity. The char yields were in the range $18-21 \mathrm{wt}-\%$ on daf basis and the fluctuations are attributed to the manual collection procedure. Hydrogen yields were negligible on a mass basis. $\mathrm{C}_{4+}$ compounds analyzed in the gas phase are shown along the organic liquid (OL) yield. For all catalysts tested, towards higher B:C ratios the yield of gas, reaction water, and coke showed a decreasing trend, while the OL yield increased. Towards higher B:C ratios, the $\mathrm{C}_{2}$ and $\mathrm{C}_{3}$ olefin yields decreased. For all catalysts, the yield of gas and water was only markedly enhanced at the lowest $\mathrm{B}: \mathrm{C}$ ratio while their changes were minor towards higher $\mathrm{B}: \mathrm{C}$ ratios. Taking Figure $2 \mathrm{~b}$ as an example, the effect of different catalyst masses at the same B:C ratio is illustrated for 151 and $15 \mathrm{~g}$ of CBV55 at B:C $\sim 6$ : Operating at reduced catalyst loadings ( $15 \mathrm{~g}$ ) compared to $151 \mathrm{~g}$ catalyst resulted in lower yields of gas (from 32.6 to $24.8 \mathrm{wt}-\%$ ), reaction water (from 22.3 to $21.0 \mathrm{wt}-\%$ ), and coke (from 2.2 to $1.1 \mathrm{wt}-\%$ ), while the yield for the sum of organic liquid and $\mathrm{C}_{4}+$ increased (from 15.2 to $20.5 \mathrm{wt}-\%$ ). A similar comparison can be made for mesoCBV55 when comparing the product yields at $\mathrm{B}: \mathrm{C} \sim 10$ and $\sim 11$ when using $20 \mathrm{~g}$ or $100 \mathrm{~g}$ of catalyst.

Lower gas yield for run Z803 (24 g CBV80, B:C = 9.9) and run Z503 (15 g CBV55, B:C = 6.5) may be attributed to the short runtime at the reduced mass of catalyst loaded. For the lower mass of catalyst loaded, the olefin concentration may peak within the first 5-10 min of operation after which it rapidly declines, and due to the gas sampling interval of $\sim 10$ min the maximum olefin concentration may not have been captured. 

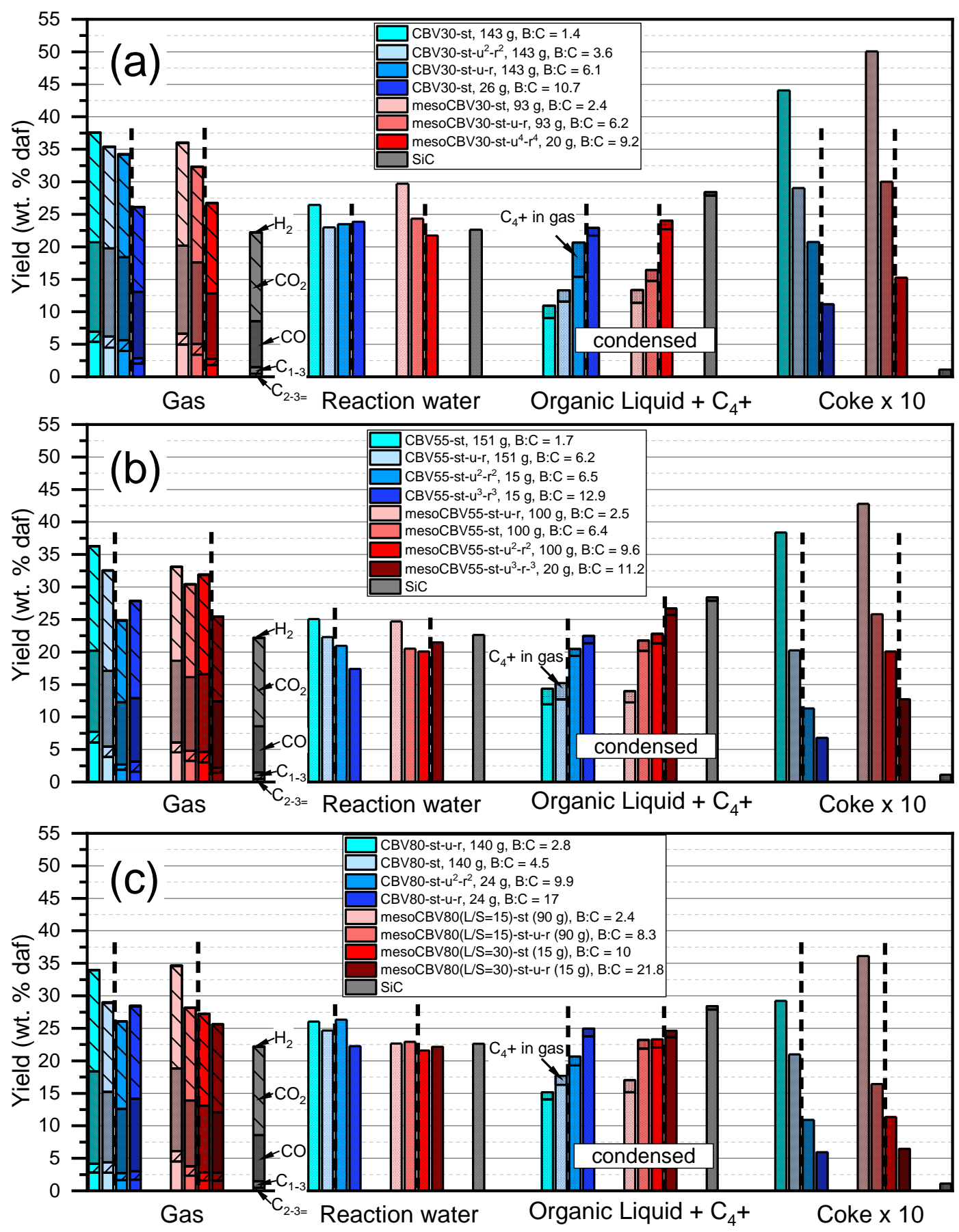

Figure 2. Product distributions (except char) for a) the parent (experiments Z301-Z304) and the mesoporous CBV30 (experiments MZ301-MZ303), for b) the parent (experiments Z501-Z504) and the mesoporous CBV55 (experiments MZ501MZ304), and for c) the parent (experiments Z801-Z804) and the mesoporous CBV80 (experiments MZ801-MZ804). Results with $\mathrm{SiC}$ (grey bars) shown for reference. Char yields were within 18-21 wt-\% of daf biomass. For increasing B:C in each product group, the dashed vertical lines indicate a switch to a lower catalyst mass. 


\subsection{Comparison of oil properties}

For analysis of the obtained liquid products, Karl Fischer titration, elemental analysis and GC-MS/FID were conducted for the oil fractions obtained at the $4{ }^{\circ} \mathrm{C}$, ESP, and $-60{ }^{\circ} \mathrm{C}$ condensation stage, as well as for the mixture of water fractions obtained at the $4{ }^{\circ} \mathrm{C}$ and $-60^{\circ} \mathrm{C}$ stage. For analysis of the TAN and evaporation behavior of the oils, a portion of the oil fractions obtained at the different condensation stages were combined to an "OF mix" according to their yields at each condensation stage. Table S2 in the SI summarizes the characterization of the non-catalytic reference oil obtained when vapors were passed over a SiC bed. Table S3-S6 (SI) summarize the properties of the obtained liquid product fractions for experiments Z301 to Z304 using the parent CBV30, while Table S7-S9 (SI) summarize the properties of the obtained liquid product fractions using mesoporous CBV30 (experiments MZ301 to MZ303). Similarly, Table S10-S13 (SI) and Table S18-S21 (SI) give an overview of the properties of the obtained liquid product fractions using the parent CBV55 and CBV80, while Table S14-S17 (SI) and Table S22-S25 (SI) summarize properties of the liquid product fractions obtained when using the desilicated versions of CBV55 and CBV80 as catalyst.

Table 3 and Table 4 compare the yield of the phase separated oil fractions and their properties (moisture, oxygen content on dry basis (wt-\% O, d.b.), TAN, and evaporation behavior) for the tests conducted with the two different reactor sizes of $\sim 300 \mathrm{ml}$ and $\sim 60 \mathrm{ml}$ catalyst volume, respectively. The stated TAN refers to the "wet" oil samples, i.e. the oil fraction including the dissolved water. Overall, the TAN of the oils increased with the oil's oxygen content (Figure 3), which was also observed by others [60]. From heating the oil to $500^{\circ} \mathrm{C}$ in a TGA (Pt crucible with lid, $10^{\circ} \mathrm{C} / \mathrm{min}$ heating rate, $150 \mathrm{ml} / \mathrm{min}$ flowrate $\mathrm{N}_{2}$ ), the mass fraction remaining at 300 and $500{ }^{\circ} \mathrm{C}$ with respect to the dry organics content of the oil is stated. The TGA curves are provided as SI, Fig. S19-S21. General trends observed with oils obtained with 90-151 g catalyst (Table 3) are that for each catalyst the yield of the phase separated oil fraction but also the moisture content, oxygen content and acidity (TAN) increased towards higher cumulative B:C ratios. This is attributed to the loss in catalyst activity for vapor deoxygenation. When comparing the remaining mass percentage upon reheating the oils obtained with 90-151 g catalyst (Table 3), it can be seen that the charring tendency was markedly decreased compared to the $\mathrm{SiC}$ oil. The evaporation behavior improved most for oils collected at low B:C ratio with the lowest oxygen content. The oils obtained from B:C = 2.8 and B:C $=4.5$ using CBV80 showed a markedly improved evaporation behavior (Table 3 and Fig. S21a), whereas the TGA curves (see Fig. S21a) of oils obtained at B:C $=9.9$ and B:C $=17$ closely resembled the $\mathrm{SiC}$ oil. The clear improvement in evaporation behavior at low B:C ratio was also observed for the oils derived from mesoCBV80; however, the TGA curves stayed below the $\mathrm{SiC}$ oil even for the oils obtained at $\mathrm{B}: \mathrm{C}=22$ (see Fig. $\mathrm{S} 21 \mathrm{~b}$ ), which indicates a prolonged activity compared to the parent CBV80 in mild cracking of compounds which are prone to charring upon heating, like sugars and aldehydes. 
Table 3. Overview of the yield and properties of the phase separated oil fraction (OF) obtained with $\sim 300 \mathrm{ml}$ catalyst volume, corresponding to $90-151 \mathrm{~g}$. From heating the oils to $500^{\circ} \mathrm{C}$ in a TGA (Pt crucible with lid, $10{ }^{\circ} \mathrm{C} / \mathrm{min}$ heating rate, $150 \mathrm{ml} / \mathrm{min}$ flowrate $\mathrm{N}_{2}$ ), the mass fraction remaining at 300 and $500{ }^{\circ} \mathrm{C}$ with respect to the dry organics content of the oils is stated.

\begin{tabular}{|c|c|c|c|c|c|}
\hline Experiment & $\begin{array}{c}\text { OF yield } \\
\text { [wt-\% of daf } \\
\text { biomass] }\end{array}$ & $\begin{array}{l}\mathrm{H}_{2} \mathrm{O} \\
{[\%]}\end{array}$ & wt- $\%$ O (d.b.) & $\begin{array}{c}\mathrm{TAN} \\
{[\mathrm{mg} \mathrm{KOH} / \mathrm{g}]}\end{array}$ & $\begin{array}{l}\text { Solid remains (wt- } \% \text { d.b.) at } \\
\quad 300{ }^{\circ} \mathrm{C} / 500{ }^{\circ} \mathrm{C}\end{array}$ \\
\hline $\mathrm{SiC}$ & 19.4 & 14.7 & 21.4 & 54.4 & $44.5 / 16.9$ \\
\hline $\mathrm{Z} 301(\mathrm{~B}: \mathrm{C}=1.4)$ & 8.5 & 0.4 & 3.2 & 0.3 & $8.0 / 2.9$ \\
\hline $\mathrm{Z} 302(\mathrm{~B}: \mathrm{C}=3.6)$ & 11.5 & 1.4 & 9.3 & 3.0 & $18.6 / 8.0$ \\
\hline $\mathrm{Z} 303(\mathrm{~B}: \mathrm{C}=6.1)$ & 15.8 & 1.9 & 12.7 & 5.7 & $25.3 / 10.3$ \\
\hline $\operatorname{MZ301}(\mathrm{B}: \mathrm{C}=2.4)$ & 10.1 & 1.1 & 5.9 & 2.5 & $15.5 / 4.5$ \\
\hline $\operatorname{MZ302}(\mathrm{B}: \mathrm{C}=6.2)$ & 13.3 & 2.0 & 12.4 & 7.2 & $23.7 / 9.8$ \\
\hline Z501 (B:C = 1.7) & 9.9 & 0.8 & 5.7 & 6.4 & $19.7 / 7.1$ \\
\hline $\mathrm{Z} 502(\mathrm{~B}: \mathrm{C}=6.2)$ & 11.3 & 2.2 & 12.6 & n.a. & n.a. \\
\hline $\operatorname{MZ501}(\mathrm{B}: \mathrm{C}=2.5)$ & 11.2 & 1.3 & 7.4 & 5.0 & $24.9 / 9.8$ \\
\hline MZ502 (B:C = 6.4) & 14.9 & 2.2 & 10.1 & 7.1 & $26.0 / 11$ \\
\hline $\operatorname{MZ503}(\mathrm{B}: \mathrm{C}=9.6)$ & 18.8 & 2.7 & 12.8 & 10.8 & $32.1 / 13.8$ \\
\hline $\mathrm{Z} 801(\mathrm{~B}: \mathrm{C}=2.8)$ & 13.0 & 1.8 & 9.2 & 5.9 & $25.5 / 10.3$ \\
\hline $\mathrm{Z} 802(\mathrm{~B}: \mathrm{C}=4.5)$ & 14.5 & 3.1 & 13.6 & 7.8 & $27.2 / 10.5$ \\
\hline MZ801 (B:C = 2.4) & 13.6 & 1.6 & 10.4 & 5.5 & $23.0 / 10.6$ \\
\hline MZ802 (B:C = 8.3) & 18.2 & 3.1 & 13.5 & 13.5 & $29.7 / 13.1$ \\
\hline
\end{tabular}

The results obtained with 15-26 g catalyst (Table 4) show that for the catalysts for which two runs were conducted (CBV55, CBV80, and mesoCBV80), the yield, oxygen content, and TAN of the oils increased towards higher B:C ratios. 20-26 g of parent and mesoporous CBV30 achieved mild deoxygenation, indicating that the properties of the $\mathrm{SiC}$ reference oil may only be approached at B:C ratios $>10$. Utilizing $20 \mathrm{~g}(\mathrm{MZ504})$ instead of $100 \mathrm{~g}$ (MZ503) mesoCBV55 and operating to B:C $\sim 10$ lead to a clear jump in oxygen concentration from 12.8 to $18.2 \mathrm{wt}-\%$, as well as an $80 \%$ higher loss of organics to the aqueous phase (see Table S16-S17, SI). This is attributed to a lower degree of conversion of reactive oxygenates like sugars, aldehydes, ketones, and acids, which correlates with an increase in TAN of the phase separated oil fraction from 11 to $27 \mathrm{mg} \mathrm{KOH} / \mathrm{g}$. $15 \mathrm{~g}$ of mesoCBV80 $(\mathrm{L} / \mathrm{S}=30)$ had a high capacity for mild deoxygenation as the properties of the SiC reference oil would only be approached at B:C ratios $>22$. In contrast, for the parent CBV80 the oils' oxygen content more closely approached the $\mathrm{SiC}$ oil at $\mathrm{B}: \mathrm{C}=17$, even though $41 \%$ more catalyst (by mass) was loaded. The poor performance towards high $\mathrm{B}: \mathrm{C}$ ratios of the parent $\mathrm{CBV} 80$ could be attributed to the inaccessibility of acid sites once a coke envelope covered the crystals and blocked the majority of pore mouth entries, while the more open crystal structure of the mesoCBV80 has a higher tolerance towards deactivation by coke. Monitoring of the composition of the hot vapors would be required to corroborate this point, but was not possible in this work. 
Table 4. Overview of yield and properties of the phase separated oil fraction (OF) obtained with $\sim 60 \mathrm{ml}$ catalyst volume, corresponding to $15-26 \mathrm{~g}$. From heating the oils to $500{ }^{\circ} \mathrm{C}$ in a TGA (Pt crucible with lid, $10{ }^{\circ} \mathrm{C} / \mathrm{min}$ heating rate, $150 \mathrm{ml} / \mathrm{min}$ flowrate $\mathrm{N}_{2}$ ), the mass fraction remaining at 300 and $500{ }^{\circ} \mathrm{C}$ with respect to the dry organics content of the oils is stated.

\begin{tabular}{|c|c|c|c|c|c|}
\hline Experiment & $\begin{array}{c}\text { OF yield } \\
\text { [wt-\% of daf } \\
\text { biomass] }\end{array}$ & $\mathrm{H}_{2} \mathrm{O}[\%]$ & wt- $\%$ O (d.b.) & $\begin{array}{c}\text { TAN } \\
{[\mathrm{mg} \mathrm{KOH} / \mathrm{g}]}\end{array}$ & $\begin{array}{c}\text { Solid remains } \\
\text { (wt-\% d.b.) at } \\
300^{\circ} \mathrm{C} / 500{ }^{\circ} \mathrm{C}\end{array}$ \\
\hline $\mathrm{SiC}$ & 19.4 & 14.7 & 21.4 & 54.4 & $44.5 / 16.9$ \\
\hline $\mathrm{Z} 304(\mathrm{~B}: \mathrm{C}=10.7)$ & 16.7 & 3.4 & 16.2 & 20.1 & $33.8 / 15.6$ \\
\hline $\operatorname{MZ303}(\mathrm{B}: \mathrm{C}=9.2)$ & 17.2 & 2.9 & 15.8 & 23.6 & $29.7 / 13.1$ \\
\hline $\mathrm{Z} 503(\mathrm{~B}: \mathrm{C}=6.5)$ & 14.8 & 4.1 & 17.1 & 26.0 & $34.5 / 13.3$ \\
\hline $\mathrm{Z} 504(\mathrm{~B}: \mathrm{C}=12.9)$ & 17.7 & 3.9 & 20.7 & 22.8 & $34.2 / 13.4$ \\
\hline $\operatorname{MZ504}(\mathrm{B}: \mathrm{C}=11.2)$ & 20.1 & 3.3 & 18.2 & 26.9 & $36.5 / 16.8$ \\
\hline $\mathrm{Z} 803(\mathrm{~B}: \mathrm{C}=9.9)$ & 16.6 & 4.1 & 16.0 & 18.5 & $42.7 / 17.6$ \\
\hline $\mathrm{Z} 804(\mathrm{~B}: \mathrm{C}=17)$ & 19.1 & 3.4 & 20.2 & 23.6 & $45.2 / 18.4$ \\
\hline $\operatorname{MZ803}(\mathrm{B}: \mathrm{C}=10)$ & 16.2 & 3.1 & 15.8 & 20.0 & $32.0 / 12.6$ \\
\hline MZ804 $(\mathrm{B}: \mathrm{C}=21.8)$ & 18.5 & 4.0 & 17.0 & 27.7 & $32.3 / 14.3$ \\
\hline
\end{tabular}

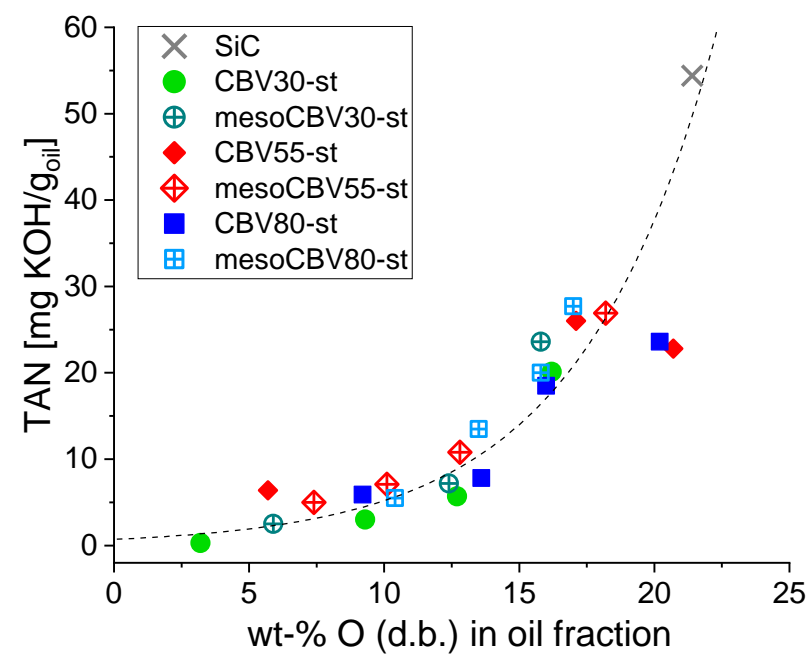

Figure 3. Correlation between TAN content and oxygen content of the phase separated oil fractions (including the dissolved water), with an exponential fit of all data points indicated as dashed line.

Fig. S22-S24 (SI) show size exclusion chromatograms of selected oils obtained from the three parent and respective mesoporous versions in comparison with the $\mathrm{SiC}$ oil. For chemically similar compounds, a higher retention volume indicates a shift to lower molecular weight, as illustrated by the retention volumes of the hydrocarbon standards. There are at least seven discernable components in the SEC trace for the SiC oil. The majority of the MW distribution appears to be located below $1000 \mathrm{Da}$, which is rather low compared to reported weight distributions extending up to $10000 \mathrm{Da}$ and $3000 \mathrm{Da}$ for non-catalytic oils derived from fast pyrolysis of wood [61] and wheat straw [43], respectively. The lower MW of our SiC reference oil can be partly attributed to the additional cracking upon contact of the vapors with fine char containing a high concentration of the biomass indigenous alkaline ashes (especially $\mathrm{K}$ ) at the hot gas filter [2,62-65] and partly to the effect of the $\mathrm{SiC}$ bed. Oils obtained at low B:C from both parent and mesoporous HZSM-5 showed a more intense differential refractive index (DRI) response at higher retention volume, which indicates a higher concentration or narrower MW distribution of lower MW compounds. This observation agrees well with the increased aromatic character determined by GC-MS/FID and NMR (vide infra). After extended feeding of biomass, the intensity of the low 
MW contribution decreased and the shoulders attributed to the higher MW contributions started to appear in the chromatograms (see Fig. S22-S24). For the MW distributions of the CBV55 derived oils it has to be noted that the oils from the two catalysts were not obtained at identical conditions. The parent CBV55 oils were collected for $\mathrm{B}: \mathrm{C}=0-1.1$ and $\mathrm{B}: \mathrm{C}=3.6-6.2$, while both oils for the mesoCBV55 were obtained starting the vapor upgrading at $\mathrm{B}: \mathrm{C}=0$. Very similar MW distribution resulted for the oil obtained within the narrower B:C interval of 3.66.2 over the partly coked CBV55 (151 g), compared to the oil obtained at B:C $=0-9.6$ using mesoCBV55 (100 g).

The GC-MS/FID analysis of the oils is shown in Figure 4a-c. Within the GC-quantifiable range, monoaromatics (MAR) were the main product for CBV30 derived oils at B:C $=1.4$, with a yield of $4.2 \mathrm{wt}-\%$ of fed biomass. At cumulative $\mathrm{B}: \mathrm{C}=6.1$, the MAR yield decreased to $2.5 \mathrm{wt}-\%$. In comparison, the mesoporous CBV30 produced slightly reduced MAR yields of $2 \mathrm{wt}-\%$ at $\mathrm{B}: \mathrm{C}=6.2$. With $151 \mathrm{~g}$ of parent CBV55 the yield of MAR at low B:C was initially close to $3 \mathrm{wt} \%$ of fed biomass. With continued feeding of biomass, the MAR yield rapidly decreased for the parent CBV55 to $1.5 \mathrm{wt}-\%$ at B:C $=6.2$. Similar MAR yields close to $3 \mathrm{wt}-\%$ were obtained using $100 \mathrm{~g}$ of mesoCBV55 at $\mathrm{B}: \mathrm{C}=2.5$. However, after prolonged exposure to pyrolysis vapors (B:C $=6.4$ and 9.6), the MAR yield of oil obtained at $\mathrm{B}: \mathrm{C}=6.4$ had decreased only slightly and only the oil obtained at B.C $=9.6$ showed a markedly reduced MAR yield of $1.9 \mathrm{wt}-\%$. This indicates that the rate of deactivation could be decreased for the mesoCBV55 compared to its parent version, resulting in prolonged activity towards higher $\mathrm{B}: \mathrm{C}$ ratios. The MAR yields at $\mathrm{B}: \mathrm{C}=2.8$ for $\mathrm{CBV} 80$ and at $\mathrm{B}: \mathrm{C}=2.4$ for mesoCBV80 were comparable (see Figure 4c). A rapid decline in monoaromatics yield to $54 \%$ of its initial yield was observed for CBV80 at $\mathrm{B}: \mathrm{C}=4.5$, while the operation of mesoporous $\mathrm{CBV} 80$ to a higher $\mathrm{B}: \mathrm{C}=8.3$ resulted in a decrease to $64 \%$ of its initial yield. It is noted that besides deoxygenated products, also the yield of oxygenates, especially ketones, aldehydes, furans, acids and esters within the GC-identifiable range were higher for the mesoporous version. A higher fraction of GC-identifiable compounds agrees with an improved evaporation behavior (Table 4) and can be attributed to enhanced cracking reactions of the pyrolysis vapors over the mesoporous CBV80, yielding vapors with lower MW and lower boiling point. For all catalysts, a clear drop in MAR yields was observed for the oils obtained at reduced catalyst loadings. In accordance with the increase in oxygen and TAN towards higher B:C ratios, a breakthrough of oxygenated compounds like acids, furans, aldehydes, ketones and ethers was observed.

No significant differences were observed regarding the selectivity to monoaromatics when comparing the mesoporous with its parent versions for the same reactor configuration (300 and $60 \mathrm{ml}$ ), and a drop in selectivity to BTX was observed at increased WHSV (lower catalyst mass) at similar B:C ratios (see Fig. S25-S27, SI). 

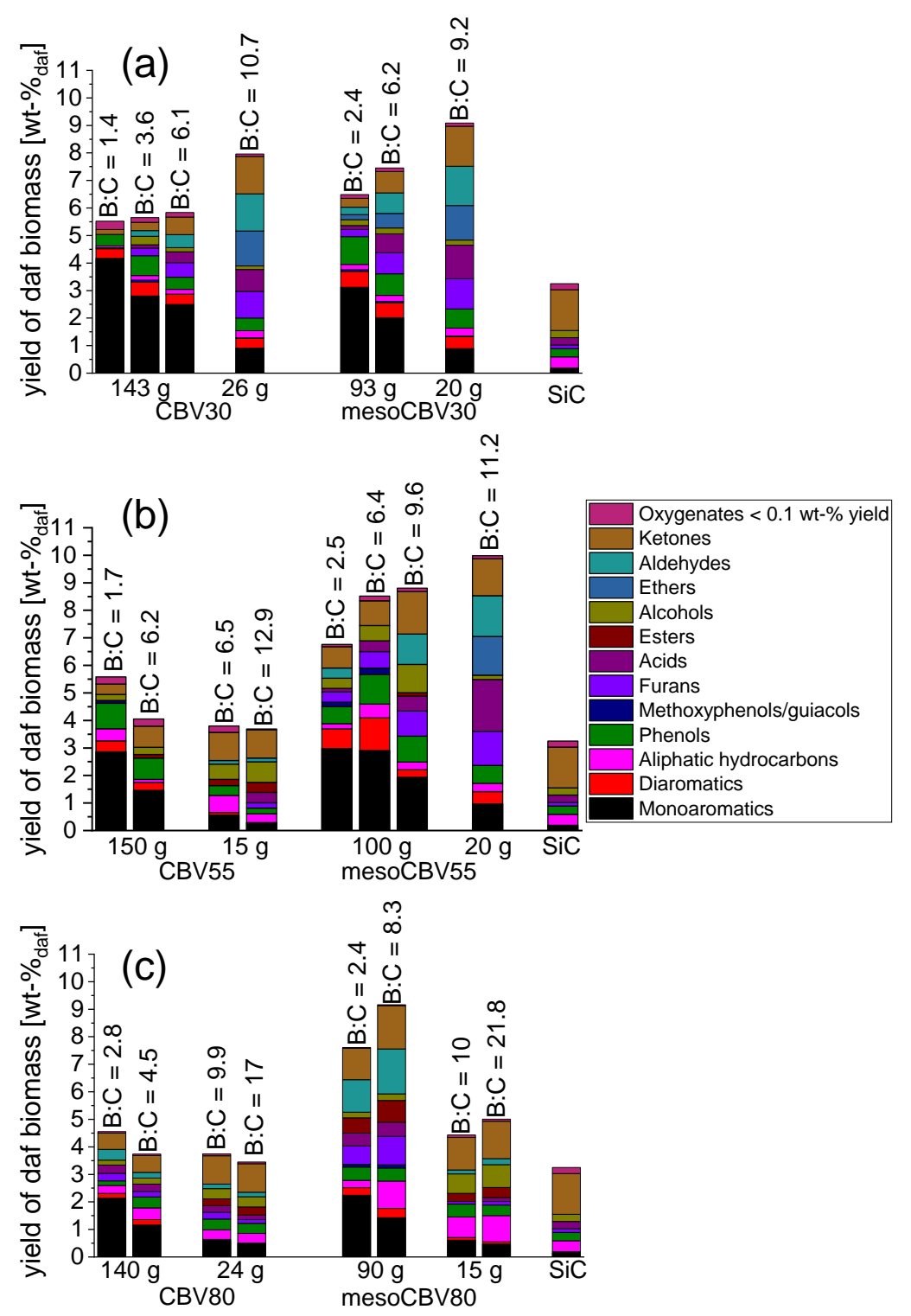

Figure 4. Yields of GC identifiable products obtained from a) CBV30 and mesoCBV30, from b) CBV55 and mesoCBV55, and from c) CBV80 and mesoCBV80. Nitrogen containing compounds and PAH within the GC range were below $0.08 \mathrm{wt}-\%$ yield and are not shown. Oxygenates present in yields $<0.1 \mathrm{wt}-\%$ were grouped.

While GC-MS/FID analysis allows detailed determination of the chemical composition, it only identifies a fraction of the oil since up to $50 \%$ of the oils mass may remain/char at the $\mathrm{GC}$ injection $\left(250{ }^{\circ} \mathrm{C}\right)$ as seen from evaporation of the oils in a TGA (see Fig. S19-S21). To analyze the chemical composition of the whole oils, the $\mathrm{SiC}$ oil and oils obtained for $100 \mathrm{~g}$ mesoCBV55-st at $\mathrm{B}: \mathrm{C}=2.5$ and $\mathrm{B}: \mathrm{C}=9.6$ were subjected to ${ }^{1} \mathrm{H},{ }^{13} \mathrm{C}$ NMR and 2D HSCQ NMR analysis, respectively. A comparison of the processed ${ }^{1} \mathrm{H}$ NMR spectra for these three oils is found in Fig. S28, SI. The relative distribution of the different chemical groups was obtained by assigning the functional groups to their chemical shift ranges, and excluding the peak area contributions of water (3.7-3.3 ppm) and the DMSO solvent $(2.5 \mathrm{ppm})$. The obtained hydrogen percentages are summarized in Table 5 with the assigned protons marked underlined. A six-fold increase of the $\mathrm{H} \%$ in the sum of $-\mathrm{CHO}$ and $\mathrm{ArOH}$ compared to the $\mathrm{SiC}$ oil results for oil at $\mathrm{B}: \mathrm{C}=2.5(4.3 \%)$, which then decreased to $3.4 \%$ for oil obtained at $\mathrm{B}: \mathrm{C}=9.6$. The concentration of protons within aromatics and conjugated alkenes jumps from $12 \%(\mathrm{SiC})$ to $41 \%(\mathrm{~B}: \mathrm{C}=2.5)$, 
after which it decreases to $31 \%$ at $\mathrm{B}: \mathrm{C}=9.6$ since the coke formation leads to reduced aromatization activity. For the group of aliphatic $\mathrm{OH},-\mathrm{C} \underline{\mathrm{H}}=\mathrm{C} \underline{\mathrm{H}}-$, and $\mathrm{Ar}-\underline{\mathrm{C}}_{2}-\mathrm{O}-\mathrm{R}$, a clear drop in concentration from 4.6 to $1.7 \%$ is observed for mesoCBV55, $\mathrm{B}: \mathrm{C}=2.5$, which increases to $3.5 \%$ for oil collected at $\mathrm{B}: \mathrm{C}=9.6$. Similar observations hold true for the protons bound in ether and methoxy groups $\left(\mathrm{R}-\mathrm{C}_{2}-\mathrm{O}-\mathrm{R}\right.$ and $\left.\mathrm{CH}_{3}-\mathrm{O}-\mathrm{R}\right)$ as well as aliphatic protons. The $60-70 \%$ lower proton concentration in oxygen-containing groups $(6-3 \mathrm{ppm})$ is in agreement with the reduction in the oil's oxygen content by $65 \%$ compared to the $\mathrm{SiC}$ oil.

${ }^{13} \mathrm{C}$ NMR analysis of the oils provides spectra with less overlap of chemical shifts compared to ${ }^{1} \mathrm{H}$ NMR. Fig. S29 (SI) compares the spectra of the mix OF obtained over SiC, mesoCBV55 at B:C $=2.5$ and mesoCBV55 at $\mathrm{B}: \mathrm{C}=9.6$, respectively, and Table 6 summarizes the carbon content as a percentage within a given chemical shift range. The assignment of chemical shift regions was conducted according to Mante et al. [66] and Joseph et al. [67]. ${ }^{13} \mathrm{C}$ NMR confirms a clear influence of the catalyst on the chemical composition of the bio-oil. The noncatalytic oil shows a high amount of oxygenated compounds with carbonyl, carbohydrates and methoxy/hydroxyl carbons constituting $27.6 \%$ the total C. For the oil obtained using $100 \mathrm{~g}$ mesoCBV55 at $\mathrm{B}: \mathrm{C}=2.5$, the fraction of carbonyl, carbohydrates and methoxy/hydroxyl carbons is reduced to $8.3 \%$, and it increases to $15.2 \%$ for oil collected at $\mathrm{B}: \mathrm{C}=9.6$. The carbon content of aromatics including olefins and phenolics almost doubled from $36 \%$ in the $\mathrm{SiC}$ oil to $65.5 \%$ in the oil obtained at $\mathrm{B}: \mathrm{C}=2.5$, while its concentration decreased to $50.4 \%$ for oil obtained at $\mathrm{B}: \mathrm{C}=9.6$. This is in agreement with the reduced aromatization activity and dilution of the initially highly aromatic oil with non-aromatic (oxygenated) compounds as shown by the increased carbon concentration of carbonyl, carbohydrates, alcohols, ethers, and lignin derived methoxy-groups. According to Mante et al. [66], signals at 140-160 ppm and 105-125 ppm are characteristic of aromatic carbons in phenol, and methoxylated phenols related to guaiacyl and syringyl lignin groups. This classification indicates that the $\mathrm{C}$ within phenols and methoxylated phenols at $\mathrm{B}: \mathrm{C}=9.6$ reaches a similar level as for oil obtained with $\mathrm{SiC}$, while the contribution of non-oxygenated aromatics is still markedly enhanced (see Table 6). Despite slight differences in the chemical shift assignment, the ${ }^{13} \mathrm{C}$ NMR analysis of our non-catalytic reference oil agrees well with the ${ }^{13} \mathrm{C}$ NMR analysis reported by Negahdar et al. [38] for wheat straw bio-oil, which showed 35.7\% alkyl C (54-1 ppm), 12.4\% carbonyl (215-163 ppm), 5.6\% carbohydrates ( $103-70 \mathrm{ppm})$, and 30.1\% aromatics (163-103 ppm).

2-D NMR spectra lower the likelihood of overlapping because the signals are spread out into two dimensions. The heteronuclear single-quantum correlation spectroscopy (HSQC) correlates chemical shifts of carbons and protons in a phase sensitive way. Methine $(=\mathrm{CH}-)$ and methyl $\left(-\mathrm{CH}_{3}\right)$ groups appear as positive signals (blue in Fig. S30), whereas methylene groups $\left(=\mathrm{CH}_{2}\right.$ or $\left.-\mathrm{CH}_{2}-\right)$ show negative intensity (red in Fig. S30). Upon use of catalyst (100 g mesoCBV55-st), the oil obtained at B:C $=2.5$ shows a clear reduction in -CH-O- and -O-CH-Ogroups, mainly present in sugars. In addition, a reduction in the aldehydes and a clear enhancement of the aromatics is observed, in agreement with the 1D NMR results. For the oil collected after prolonged exposure to straw pyrolysis vapors at $\mathrm{B}: \mathrm{C}=9.6$, a higher concentration of - $\mathrm{CH}-\mathrm{O}-$ and $-\mathrm{O}-\mathrm{CH}-\mathrm{O}-$ groups is noted, however still reduced compared to the $\mathrm{SiC}$ oil. In contrast, the concentration of aldehydes of the oil collected at $\mathrm{B}: \mathrm{C}=9.6$ shows similar intensities as the non-catalytic reference oil. 
Table 5. Hydrogen percentage based on the ${ }^{1} \mathrm{H}$ NMR analysis of three oils (mix OF) obtained from passing straw fast pyrolysis vapors over 1) $\mathrm{SiC}, 2$ ) mesoCBV55-st at $\mathrm{B}: \mathrm{C}=2.5$, and 3) mesoCBV55-st at $\mathrm{B}: \mathrm{C}=9.6$.

\begin{tabular}{|c|c|c|c|c|}
\hline Assignment & $\begin{array}{l}\text { Chemical shift } \\
\text { range (ppm) }\end{array}$ & $\mathrm{SiC}$ & $\begin{array}{c}\text { mesoCBV55-st-u-r, } \\
B: C=2.5\end{array}$ & $\begin{array}{c}\text { mesoCBV55-st- } \mathrm{u}^{2}-\mathrm{r}^{2}, \\
\text { B:C }=9.6\end{array}$ \\
\hline$-\mathrm{COO} \underline{\mathrm{H}}$ & $12.5-11.0$ & $0.15 \%$ & $0.04 \%$ & $0.17 \%$ \\
\hline$-\mathrm{C} \underline{\mathrm{HO}}, \mathrm{ArOH}$ & $11-8.2$ & $0.69 \%$ & $4.33 \%$ & $3.42 \%$ \\
\hline $\begin{array}{l}\text { aromatics, } \\
\text { conj. alkene } \mathrm{H}\end{array}$ & $8.2-6$ & $11.95 \%$ & $41.29 \%$ & $31.43 \%$ \\
\hline $\begin{array}{l}\text { aliphatic } \mathrm{OH}, \\
-\mathrm{C} \underline{\mathrm{H}}=\mathrm{C} \underline{\mathrm{H}}-,, \overline{\mathrm{Ar}}-\mathrm{C}_{2}- \\
\mathrm{O}-\mathrm{R}\end{array}$ & $6-4.2$ & $4.65 \%$ & $1.73 \%$ & $3.49 \%$ \\
\hline $\begin{array}{l}\mathrm{R}-\mathrm{C}_{2}-\mathrm{O}-\mathrm{R}, \\
\mathrm{C}_{3}{ }_{3}-\mathrm{O}-\mathrm{R}\end{array}$ & $4.2-3$ & $9.58 \%$ & $2.72 \%$ & $6.08 \%$ \\
\hline $\begin{array}{l}-\mathrm{C} \underline{H R}-\mathrm{C}=\mathrm{O}, \\
-\mathrm{C} \underline{\mathrm{H}} \mathrm{R}-\mathrm{C}=\mathrm{C} \text {, aliphatic } \underline{\mathrm{H}}\end{array}$ & $3.0-2.0$ & $48.41 \%$ & $40.38 \%$ & $38.48 \%$ \\
\hline aliphatic $\underline{\mathrm{H}}$ & $2.0-0$ & $24.55 \%$ & $9.51 \%$ & $16.92 \%$ \\
\hline
\end{tabular}

Table 6. Carbon percentage based on the ${ }^{13} \mathrm{C}$ NMR analysis of three oils obtained from passing straw fast pyrolysis vapors over 1) $\mathrm{SiC}, 2$ ) mesoCBV55-st at $\mathrm{B}: \mathrm{C}=2.5$, and 3) mesoCBV55-st at $\mathrm{B}: \mathrm{C}=9.6$.

\begin{tabular}{|l|c|c|c|c|}
\hline Assignment & $\begin{array}{c}\text { Chemical shift } \\
\text { range (ppm) }\end{array}$ & SiC & $\begin{array}{c}\text { mesoCBV55-st-u-r, } \\
\text { B:C = 2.5 }\end{array}$ & $\begin{array}{c}\text { mesoCBV55-st-u²- } \\
\text { r }^{2}, \text { B:C = 9.6 }\end{array}$ \\
\hline Aldehydes, ketones & $220-180$ & $7.8 \%$ & $3.5 \%$ & $6.1 \%$ \\
\hline $\begin{array}{l}\text { CO groups (carboxylic } \\
\text { acids and derivatives) }\end{array}$ & $180-160$ & $7.6 \%$ & $1.7 \%$ & $2.6 \%$ \\
\hline $\begin{array}{l}\text { Aromatic carbons in } \\
\text { phenol }\end{array}$ & $160-140$ & $12.6 \%$ & $8.9 \%$ & $12.7 \%$ \\
\hline Aromatics and olefins & $140-125$ & $9.1 \%$ & $42.3 \%$ & $21.7 \%$ \\
\hline $\begin{array}{l}\text { Methoxylated phenols } \\
\text { related to guaiacyl and } \\
\text { syringyl lignin }\end{array}$ & $125-105$ & $14.2 \%$ & $14.3 \%$ & $16.0 \%$ \\
\hline $\begin{array}{l}\text { Levoglucosan, } \\
\text { anhydrosugars, } \\
\text { alcohols, ethers }\end{array}$ & $105-60$ & $8.3 \%$ & $2.5 \%$ & $4.6 \%$ \\
\hline Methoxyl-group in lignin & $57-55$ & $3.9 \%$ & $0.7 \%$ & $1.9 \%$ \\
\hline Aliphatic hydrocarbons & $55-0$ & $36.4 \%$ & $26.3 \%$ & $34.3 \%$ \\
\hline
\end{tabular}


The oils obtained using the parent and hierarchical zeolites can be further compared with Van Krevelen diagrams (Figure 5-Figure 7). For oils obtained from both the parent and mesoporous zeolites, the molar H/C ratio increased with increasing $\mathrm{O} / \mathrm{C}$ ratio in a fairly linear trend. The extension of the trend towards $\mathrm{O} / \mathrm{C}=0$ indicate a $\mathrm{H} / \mathrm{C}$ ratio close to 1 , in agreement with a high aromaticity at more severe deoxygenation. The main deoxygenation pathways appears to be dehydration, which lowers the molar H/C ratio. For oils obtained from both the parent and mesoCBV55, the mesoCBV55 showed higher $\mathrm{H} / \mathrm{C}$ ratios, which relates to higher heating values of the oils (see Table S9-S16, SI). Both mesoporous versions of CBV80 (L/S = 15 and 30) yielded liquids with higher $\mathrm{H} / \mathrm{C}$ ratio compared to oils obtained from the parent $\mathrm{CBV} 80$. Higher $\mathrm{H} / \mathrm{C}$ ratios may result from a reduced dehydration activity of the mesoporous zeolites. An alternative possibility is that a higher fraction of hydrogen could be incorporated into the vapors due to the higher coking rates for the mesoporous zeolites. For desilicated CBV30 on the other hand the $\mathrm{H} / \mathrm{C}$ ratios of the oils did not increase.

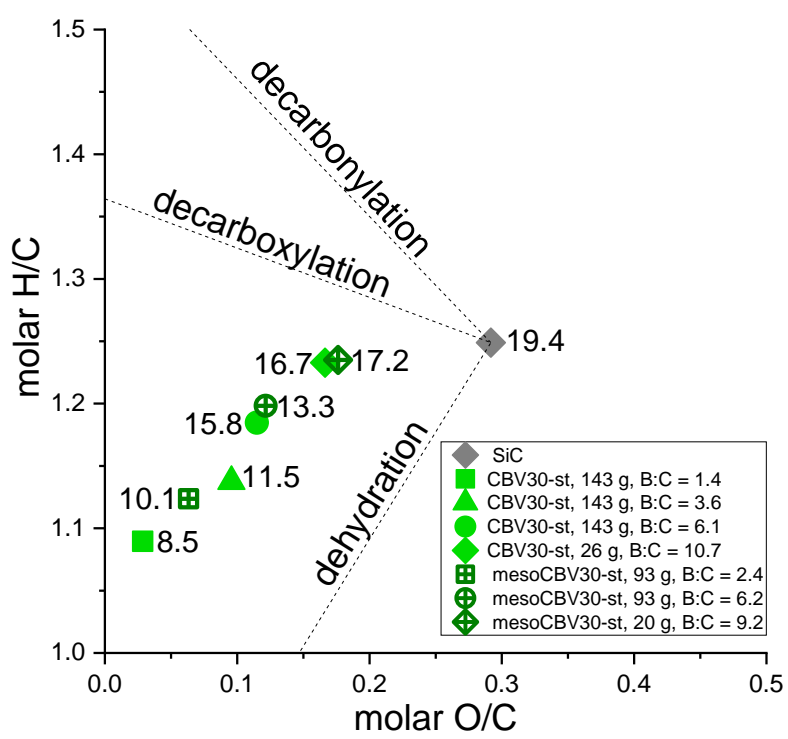

Figure 5. Molar $\mathrm{H} / \mathrm{C}$ ratio and $\mathrm{O} / \mathrm{C}$ ratio for the sum of phase separated oil fractions obtained in experiments using the parent and mesoporous CBV30 according to the conditions summarized in Table 1. Filled symbols refer to the parent CBV30 while open/crossed symbols refer to oils obtained from mesoCBV30. Oil yields (wt- $\%$ of daf biomass) are indicated for each point. 


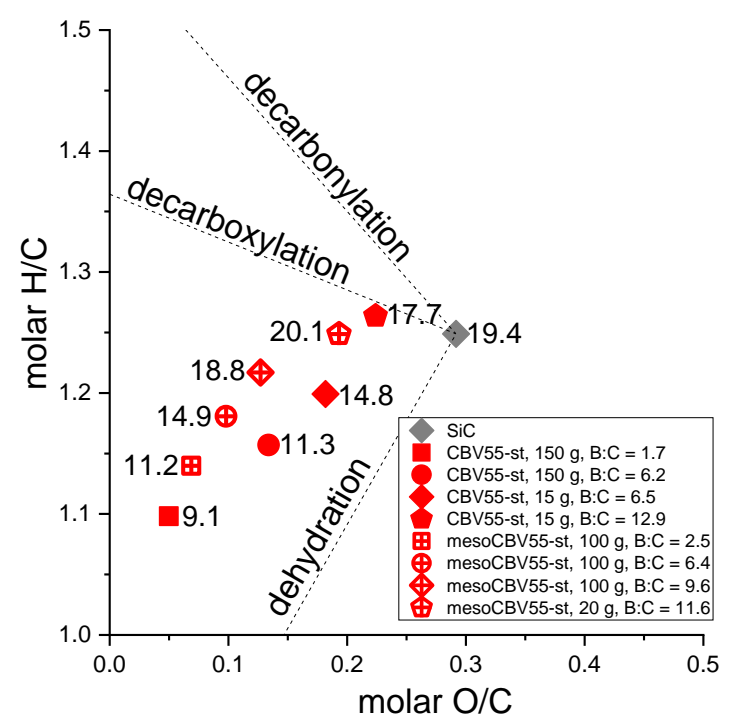

Figure 6. Molar $\mathrm{H} / \mathrm{C}$ ratio and $\mathrm{O} / \mathrm{C}$ ratio for the sum of phase separated oil fractions obtained in experiments using the parent and mesoporous CBV55 according to the conditions summarized in Table 1. Filled symbols refer to the parent CBV55 while open/crossed symbols refer to oils obtained from mesoCBV55. Oil yields (wt-\% of daf biomass) are indicated for each point.

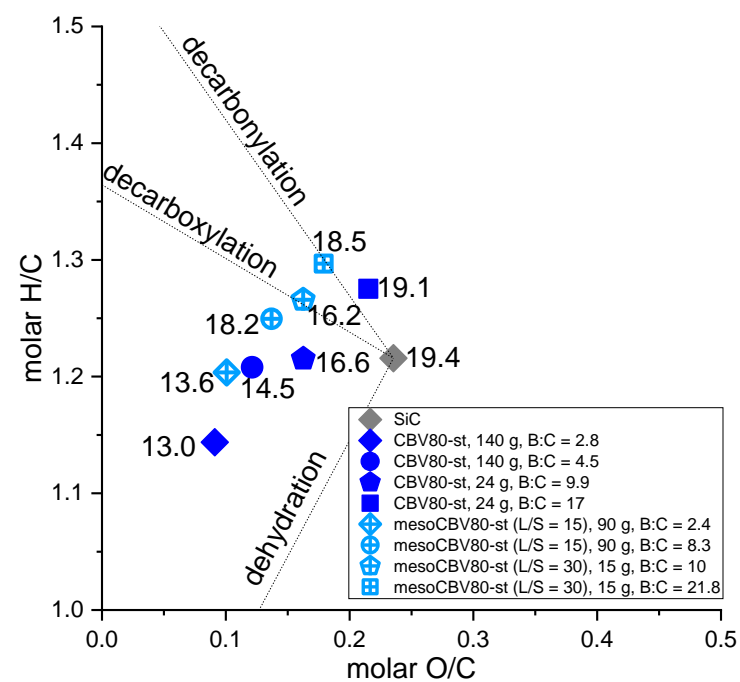

Figure 7. Molar $\mathrm{H} / \mathrm{C}$ ratio and $\mathrm{O} / \mathrm{C}$ ratio for the sum of phase separated oil fractions obtained in experiments using the parent and mesoporous CBV80 according to conditions summarized in Table 1. Full symbols refer to oils obtained using the parent CBV80 while open/crossed symbols refer to oils obtained from mesoCBV80. Oil yields (wt- $\%$ of daf biomass) are indicated for each point.

\subsection{Comparison of coking}

Comparing the coke formation for CBV30 with increasing biomass fed (Figure 8a) shows that after a rapid initial coke buildup the rate of carbon accumulation on the zeolite decreased appreciably with continued feeding of biomass. This can be attributed to a rapid reduction in the number of available (and accessible) active sites since the majority of strong Brønsted sites is expected to be rapidly poisoned by coke species. Besides coke deposition on the acid sites, the coke layer itself may continue to induce further coke formation both due to thermal coking of very reactive and unstable tar species and its mild catalytic properties. For both the parent CBV30 and 
its mesoporous version, the coking propensity was enhanced at higher catalyst loadings. This may be explained by the additional contact time of reactive pyrolysis vapors with the catalyst surface at high catalyst loadings as well as the higher chance of condensation of primary aromatic products. The introduction of mesopores clearly increased the coke formation, both for $60 \mathrm{ml}(15-26 \mathrm{~g})$ and $300 \mathrm{ml}(90-151 \mathrm{~g})$ catalyst employed compared to the parent CBV30. It is worth noting that a preliminary vapor upgrading series was conducted using $17 \mathrm{~g}$ of nonsteamed mesoCBV30. While the liquid product collection was insufficient at low B:C ratios, the combustion of the coke deposits indicated a clearly enhanced coking propensity, with more coke formed per gram of catalyst compared to upgrading over a five times larger mass of steamed mesoCBV30. The coke formation tapered off earlier for the parent CBV30 while it continued at a slightly higher rate for the mesoCBV30. The reduced rate of coke formation was correlated with a breakthrough of primary vapors as reported by Xu et al. [68].

Similarly, for CBV55 derived hierarchical HZSM-5 the coking propensity increased (Figure 8b), as $100 \mathrm{~g}$ mesoCBV55 formed 30-40\% more coke compared to $151 \mathrm{~g}$ of the parent CBV55. For $20 \mathrm{~g}$ mesoCBV55, the coking at $\mathrm{B}: \mathrm{C}=11$ was $70 \%$ higher compared to the parent $\mathrm{CBV} 55$. Besides the increased coking propensity caused by the mesopore introduction observed for the larger catalyst loadings, the higher amount of mesoCBV55 (20 g) compared to parent CBV55 (15 g) may have contributed to the increased coke yield.

For both the parent CBV80 and its mesoporous version, more coke was formed when using more catalyst (Figure 8c). The introduction of mesopores clearly increased the coke formation, especially since about $37 \%$ less catalyst was used for the mesoCBV80. It is noted that the coking of mesoCBV80(L/S $=15)$ was only slightly enhanced, while a more pronounced increase in coke formation was observed for mesoCBV80(L/S $=30)$. This is in line with the higher mesopore surface area and the higher $\mathrm{Al}$ content of the latter.

While for all catalysts the rate of carbon accumulation on the zeolite decreased with continued feeding of biomass, the coking propensity decreased in the order of reduced Al content, both for the parent HZSM-5 (CBV30 $>$ CBV55 $>$ CBV80) as well as their hierarchical counterparts. The observation that below B:C $\sim 1$ there is hardly any difference between parent and hierarchical HZSM-5 in the coke build-up rate agrees with the observations by Jia et al. [27]. 

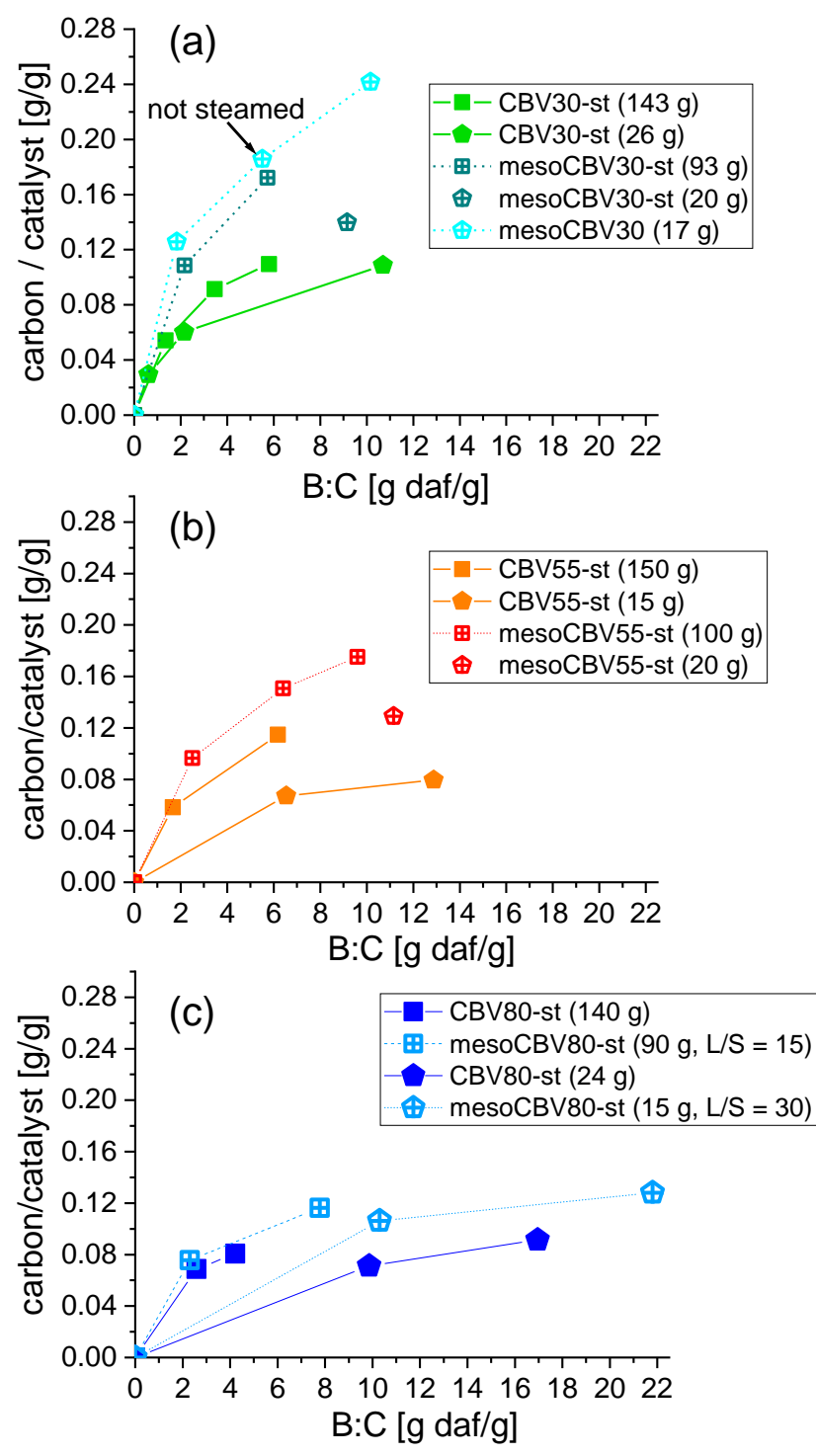

Figure 8. Build-up of carbon (as coke) on a) CBV30 and CBV30 derived hierarchical HZSM-5, b) on CBV55 and CBV55 derived hierarchical HZSM-5, and c) CBV80 and CBV80 derived hierarchical HZSM-5. Coke per mass of catalyst shown for increasing B:C ratios and experimental conditions according to Table $\mathbf{1 .}$

\subsection{Process-performance}

The energy distribution was calculated based on the mass yield of each product fraction and its heating value. The higher heating value (HHV) for char, oil, and coke was calculated based on elemental composition[69], and the HHV of the gas was calculated based on the HHV of the individual gas components. A comparison of the energy recoveries of the different products from CBV30, CBV55, CBV80 and its hierarchical versions is presented in Figure 9a-c. Energy losses to char were in the range of 26-32\%. When operated to higher cumulative B:C ratio, the energy losses to coke and gas decreased, while the energy recovery into the OL (sum of OF and WF) increased to values close to the $\mathrm{SiC}$ reference case. The energy losses to coke were highest for the mesoCBV30 and amounted to almost $10 \%$ at $\mathrm{B}: \mathrm{C}=2.4$. Using $1 / 5$ of mesoCBV30 and operating to cumulative $\mathrm{B}: \mathrm{C}=9.2$ 
decreased the energy losses to coke and gas while increasing the energy recovery to the $\mathrm{OL}$ (incl. $\mathrm{C}_{4+}$ ) to $37.6 \%$, with $16.8 \mathrm{wt}-\%$ oxygen in the oil fraction. Likewise, for CBV55 derived catalysts the energy recovery into the oil and aqueous fraction increased towards increasing B:C ratio, whereas losses to coke and gas decreased (Figure 9b). While the energy recovery of organic liquid (split in WF + OF) was highest for the $\mathrm{SiC}$ case, it is worth noting that with respect to the energy recovery into the oil phase the mesoCBV55 achieved a similar energy recovery at $\mathrm{B}: \mathrm{C}=9.6$ of $(32.8 \%)$ and at $\mathrm{B}: \mathrm{C}=11.2(30.7 \%)$ compared to the $\mathrm{SiC}$ OF $(30.4 \%)$.

Similarly, for CBV80 and mesoCBV80, the energy losses to coke and gas decreased at increasing B:C ratio, while the energy recovery of organic liquid increased to values close to the $\mathrm{SiC}$ case (Figure 9c). Akin to the results obtained for mesoCBV55 at $\mathrm{B}: \mathrm{C}=9.6$, the energy recovery of the $\mathrm{OF}$ with $\mathrm{SiC}(30.4 \%)$ was surpassed when using $90 \mathrm{~g}$ mesoCBV80(L/S=15) at $\mathrm{B}: \mathrm{C}=8.3(31.6 \%)$ and $15 \mathrm{~g}$ mesoCBV80(L/S=30) at $\mathrm{B}: \mathrm{C}=21.8$ (30.7\%). The mild deoxygenation thus decreased the losses of organics to the aqueous phase. 
(a)

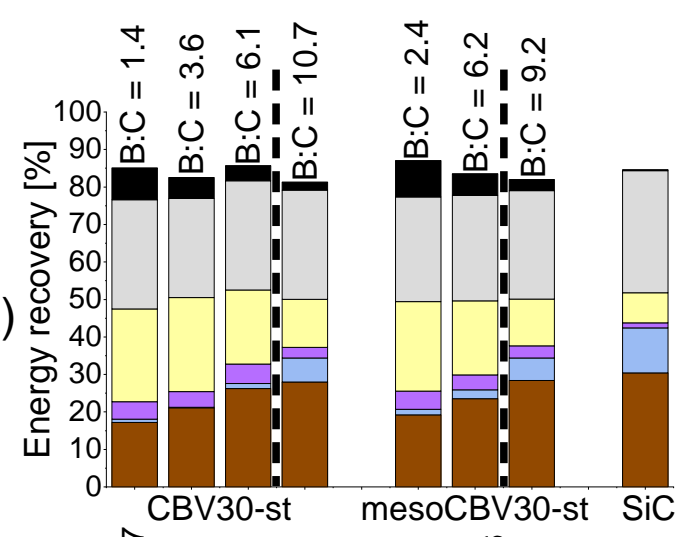

(b)

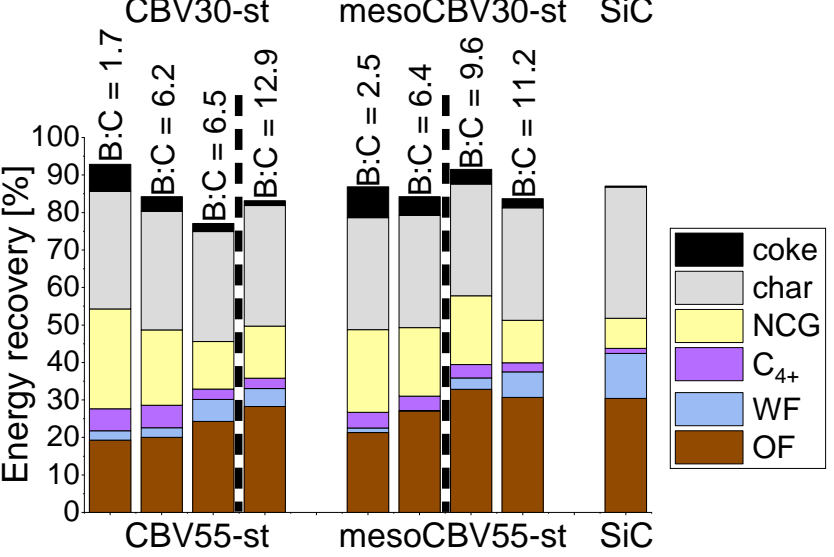

(c)

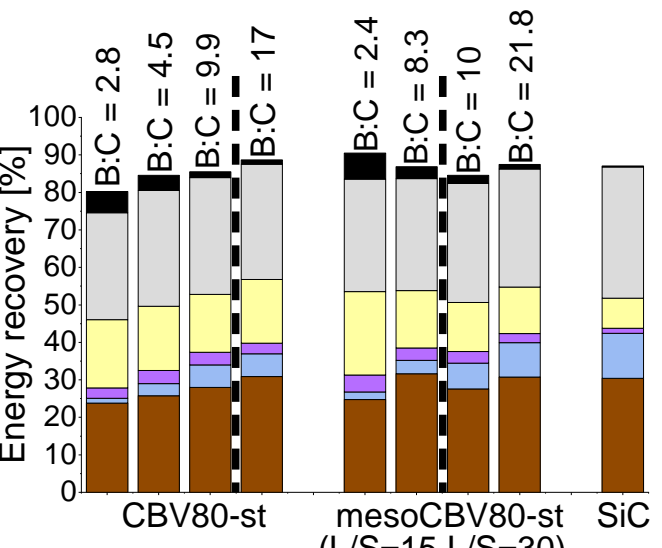

Figure 9. Energy recovery into the different product streams for experiments performed using a) CBV30 and CBV30 derived hierarchical HZSM-5, b) on CBV55 and CBV55 derived hierarchical HZSM-5, and c) CBV80 and CBV80 derived hierarchical HZSM-5. Process conditions according to Table 1. NCG, WF, and OF refer to non-condensable gases, water fraction, and oil fraction, respectively. For increasing B:C in each product group, the dashed vertical lines indicate a switch to a lower catalyst mass.

\section{Discussion}

A correlation of the extent of deoxygenation with the carbon recovery of the phase separated oil fractions is shown in Figure 10. Following Venderbosch [70], the extent of deoxygenation with respect to the $\mathrm{SiC}$ oil was calculated as $1-(\mathrm{wt}-\% \mathrm{O}$ of oil, daf)/(wt-\% O of SiC oil, daf). Depending on the amount and type of catalyst and the cumulative $\mathrm{B}: \mathrm{C}$ ratio to which the process was operated, considerable differences in deoxygenation performance resulted when compared at a certain carbon recovery of the phase separated oil fraction. A 
comparable performance based on deoxygenation and carbon yield (for $\mathrm{B}: \mathrm{C} \sim 6$ ) could be obtained using $\sim 35 \%$ lower mass of mesoporous CBV30 compared to CBV30. However, as the solid yield after desilication of CBV30 was only $50 \%$, the efforts associated with the current treatment seem not to pay off in terms of catalytic enhancement. To limit the extensive formation of mesopores the ratio of leaching solution to zeolite or the concentration of $\mathrm{NaOH}$ and thus the number of hydroxide moles available to attack the zeolite could be decreased. While the desilication of CBV55 and CBV80 led to a lower degree of mesoporosity $(0.14-0.17 \mathrm{cc} / \mathrm{g})$ compared to $0.31 \mathrm{cc} / \mathrm{g}$ for mesoCBV30, the performance of desilicated CBV55 and CBV80 was considerably improved as for the same degree of deoxygenation ( $42 \%$ ) $8 \%$ and $4.8 \%$ (absolute) higher carbon recoveries of the phase separated oil fraction were obtained, respectively (see Figure 10).

CBV80-derived mesoporous catalysts performed comparable to the parent material based on deoxygenation and carbon yield despite using 36\% lower mass. Decreased deactivation for the mesoporous versions became apparent towards extended runtime at $\mathrm{B}: \mathrm{C}>3$ for $90-140 \mathrm{~g}$ catalyst and $\mathrm{B}: \mathrm{C}>10$ for $15-24 \mathrm{~g}$ catalyst. $15 \mathrm{~g}$ of mesoCBV80(L/S=30) achieved $21 \%$ deoxygenation and $28.5 \%$ oil carbon yield at $\mathrm{B}: \mathrm{C}=22$. The use of a six times higher mass of mesoCBV80 (B:C $=8.3$ ) increased the extent of deoxygenation while obtaining a high carbon yield close to the phase separated oil fraction obtained with $\mathrm{SiC}(29 \%)$.

In Fig. S31 (SI), we present the data of Figure 10 differently and plotted the $\mathrm{C}$ recovery and oxygen content of the phase separated oil fraction obtained with $\sim 300 \mathrm{ml}$ catalyst volume (90-151 g) for increasing B:C ratios. CBV30 was deoxygenating severely at low B:C at the penalty of lower C-yield, but its deoxygenation ability rapidly declined towards increasing B:C, as seen by the high slope (Fig. S31). For the desilicated versions of CBV55 and CBV80, the slope of oxygen increase towards higher B:C ratios was lower compared to their parent versions (Fig. S31). The introduction of mesopores thus allowed to operate to higher cumulative B:C ratios when comparing oils with the same extent of deoxygenation and carbon recovery. This will reduce the costs of the process since the regeneration has to be performed less frequently, which requires a reduced number of fixed bed reactors operated in parallel [71,72].

An improved performance of the larger and less equally distributed mesopores for mesoCBV55 and mesoCBV80 compared to mesoCBV30 appears surprising at first, but may be explained by the higher preservation of the shape-selective bulk material, while the introduced mesopores improved crystal utilization compared to the parent material. In addition, the reduced acidity of the CBV55 and CBV80 derived catalysts compared to CBV30 may have led to a more favorable combination of acid site density, strength, and degree of mesoporosity. Results by Li et al. [20] and recent work by Tang et al. [73] indicates that more favorable results may be obtained for mild desilication of Al-rich HZSM-5 using $0.3 \mathrm{M} \mathrm{NaOH}$, which resulted in $V_{\text {meso }} \sim 0.13 \mathrm{cc} / \mathrm{g}$ compared to $0.3 \mathrm{cc} / \mathrm{g}$ in this work. From the present results, it can be inferred that the introduction of a low degree of mesoporosity suffices to decrease the deactivation rate by improving the site accessibility during the vapor upgrading. For the Si-rich HZSM-5 (CBV55 and CBV80), better distributed and smaller mesopores may increase site accessibility even further and reduce the loss of parent material. One way to achieve this is the addition of a surfactant like CTAB or TPAOH during the leaching, which has been found to protect the crystals and prevent uncontrolled leaching for Si-rich zeolites [74]. An advantage of the present strategy is the low cost of $\mathrm{NaOH}$ compared to surfactants. The additional costs attributed with the addition of a surfactant will have to be set-off by significant improvements in the catalyst performance. 


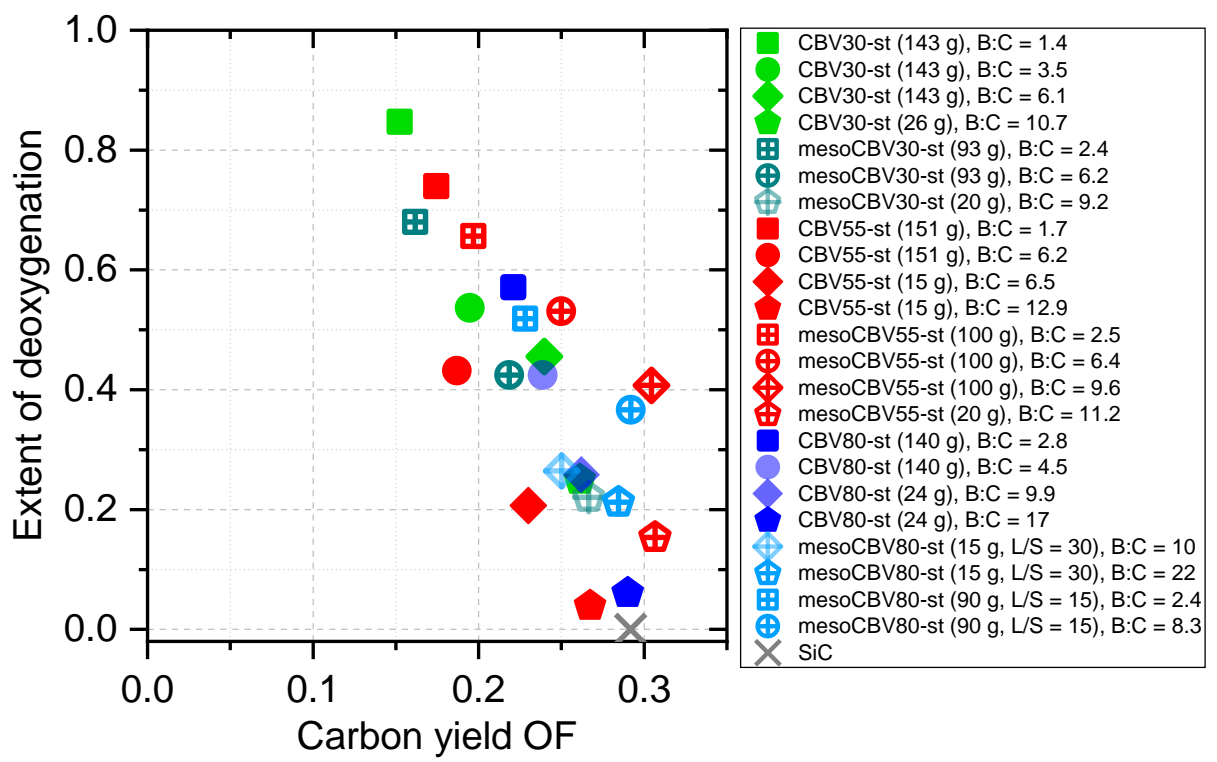

Figure 10. Correlation of the achieved deoxygenation in the OF relative to oil with 21.5 wt-\% oxygen (d.b.) obtained using $\mathrm{SiC}$ at $500^{\circ} \mathrm{C}$ and the oils' carbon yield when using parent (filled symbols) and hierarchical HZSM-5 (crossed symbols).

Correlating the energy recovery obtained in the phase separated oil fraction with the oil's TAN (Figure 11) indicates that $90-100 \mathrm{~g}$ of desilicated HZSM-5 obtained similar oil quality to their parent counterparts (140-151 g). When using 90-151 g of catalyst, the oils' TAN increased linearly towards increasing energy recovery of the oil fraction (at higher B:C). A jump to higher TAN was observed when less catalyst was utilized at $\sim 5$ times higher WHSV, which indicates incomplete conversion of acid functionalities. The gain in oil yield and energy recovery by using less catalyst thus results in lower oil quality, and operating a higher amount of catalyst towards higher $\mathrm{B}: \mathrm{C}$ ratios provided better oils at a higher energy recovery.

The enhanced coking propensity for mesoporous HZSM-5 in comparison to their parent counterparts agrees with the results obtained by others, especially for ex-situ fixed bed upgrading $[31,45,75,76]$.

In order to estimate an acid site density we assume that the number of $\mathrm{NH}_{3}$ molecules adsorbed on the catalyst surface in the $\mathrm{NH}_{3}$-TPD measurements corresponds to the number of acid sites, which are then divided by the specific surface area of the catalyst. Acid site densities for the steamed CBV30, CBV55, and CBV80 were determined to $0.8,0.54$ and 0.48 sites $/ \mathrm{nm}^{2}$, respectively, which may explain the decreasing yield of aromatics and coke in that order. For both the parent and mesoporous CBV80 materials, the acid site density was in the range of 0.4 sites $/ \mathrm{nm}^{2}$ after steaming and several reaction-regeneration cycles, which could explain their similar monoaromatics yields. 


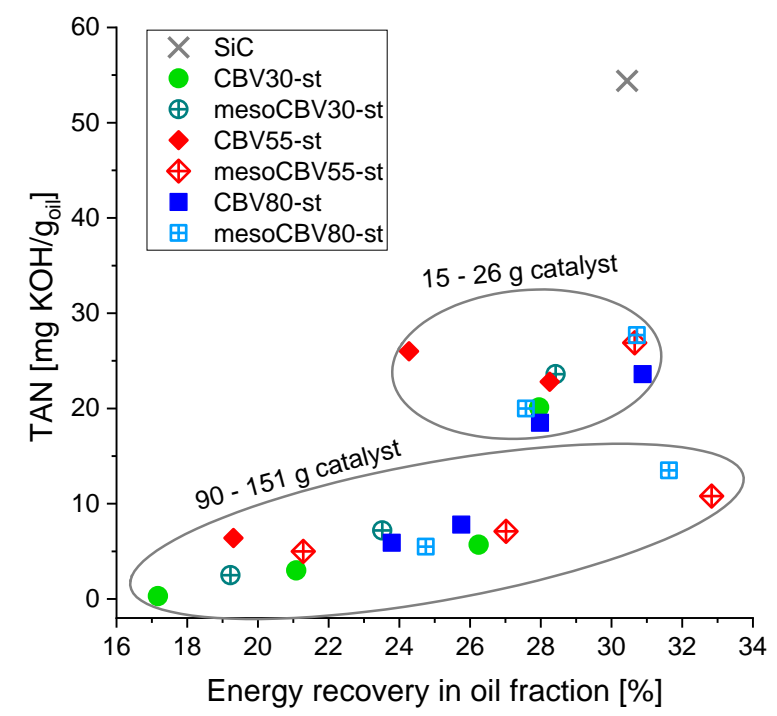

Figure 11. Energy recovery of the phase separated oil fraction (OF) versus TAN of the oils.

\section{Conclusions}

The performance of mesoporous HZSM-5 catalysts obtained by desilication of the parent zeolites with $\mathrm{Si} / \mathrm{Al}$ $\sim 16,28$, and 39 (CBV30, CBV55, and CBV80) for deoxygenating wheat straw derived pyrolysis vapors was compared to their parent versions. Addressing the three research questions posed in the introduction showed that:

i) Both the parent and hierarchical zeolites affected the product distribution by increased gas and coke production and oxygen removal from the obtained oil compared to a thermal reference case. With progressive $\mathrm{B}: \mathrm{C}$ ratio, the catalysts deactivated by coke, the oxygen content and acidity of the oils increased, and a shift towards larger molecules was observed which increased the char formation upon evaporation of the oils.

ii) When the process was operated to higher $\mathrm{B}: \mathrm{C}$ ratios of $8-10$, the desilicated versions of CBV55 and CBV80 achieved $\sim 40 \%$ deoxygenation relative to the $\mathrm{SiC}$ oil and the energy recovery of the phase separated oil fraction (31.6-32.8\%) surpassed the energy recovery of the oil fraction obtained with $\mathrm{SiC}(30.4 \%)$. The benefit is attributed to reduced losses of organics to the phase separated aqueous phase for the mildly deoxygenated oils. While $12 \%$ of the energy of the fed straw was recovered in the water fraction in the non-catalytic case, only $\sim 3 \%$ of energy was lost for the desilicated versions of CBV55 and CBV80.

iii) For desilicated CBV30, a similar deoxygenation performance compared to the conventional HZSM-5 could be maintained despite using $\sim 35 \%$ less catalyst by mass). Mesoporous HZSM-5 obtained from desilication of Sirich HZSM-5 (CBV55 and CBV80) retained their activity for a longer time compared to their original counterpart when evaluated at similar original zeolite mass and led to higher carbon recoveries for the same extent of deoxygenation. While coke yields increased by the introduction of mesopores, the tolerance towards deactivation by coke deposition during upgrading of biomass derived fast pyrolysis vapors increased, which is tentatively attributed to an improved accessibility of active sites by improved intracrystalline diffusion. 
The results indicate that fast pyrolysis of agricultural waste such as straw followed by mild deoxygenation over zeolitic catalysts may be an interesting path to obtain a feed that could be co-processed with fossil feeds in a refinery.

\section{Acknowledgements}

Lotte Nielsen is acknowledged for conducting the SEC analysis at the DTU Department of Micro- and Nanotechnology.

Partial funding of the Ph.D. project conducted at the CHEC Research Center at DTU Chemical Engineering by the Danish Energy Technology Development and Demonstration Program (EUDP project number 12454) is acknowledged.

\section{References}

[1] G.W. Huber, A. Corma, Angew. Chemie - Int. Ed. 46 (2007) 7184-7201.

[2] P.A. Case, M.C. Wheeler, W.J. DeSisto, Energy and Fuels 28 (2014) 3964-3969.

[3] A. Krutof, K.A. Hawboldt, Biomass Convers. Biorefinery 8 (2018) 775-787.

[4] A. V. Bridgwater, G.V.C. Peacocke, Renew. Sustain. Energy Rev. 4 (2000) 1-73.

[5] R. French, S. Czernik, Fuel Process. Technol. 91 (2010) 25-32.

[6] D.A. Ruddy, J.A. Schaidle, J.R. Ferrell III, J. Wang, L. Moens, J.E. Hensley, Green Chem. 16 (2014) 454-490.

[7] J. Jae, G.A. Tompsett, A.J. Foster, K.D. Hammond, S.M. Auerbach, R.F. Lobo, G.W. Huber, J. Catal. 279 (2011) 257-268.

[8] T.R. Carlson, G.A. Tompsett, W.C. Conner, G.W. Huber, Top. Catal. 52 (2009) 241-252.

[9] C. Engtrakula, C. Mukarakate, A.K. Starace, K. Magrini, A.K. Rogersb, M.M. Yung, C. Engtrakul, A.K. Rogers, T.R. Carlson, G.A. Tompsett, W.C. Conner, G.W. Huber, Catal. Today 5 (2015) 175-181.

[10] G.W. Huber, United States Patent - Catalytic Pyrolysis of Solid Biomass and Related Biofuels, Aromatic, and Olefin Compounds, Patent No.: 8864984 B2, 2014.

[11] S. Wan, C. Waters, A. Stevens, A. Gumidyala, R. Jentoft, L. Lobban, D. Resasco, R. Mallinson, S. Crossley, ChemSusChem 8 (2015) 552-559.

[12] A.G. Gayubo, A.T. Aguayo, A. Atutxa, B. Valle, J. Bilbao, J. Chem. Technol. Biotechnol. 80 (2005) 1244-1251.

[13] M. Holm, E. Taarning, K. Egeblad, C.H. Christensen, Catal. Today 168 (2011) 3-16.

[14] D.P. Serrano, R.A. García, G. Vicente, M. Linares, D. Procházková, J. Čejka, J. Catal. 279 (2011) 366380.

[15] D. Verboekend, M. Milina, S. Mitchell, J. Pérez-Ramírez, Cryst. Growth Des. 13 (2013) 5025-5035.

[16] J. Garcia-Martinez, K. Li, Mesoporous Zeolites : Preparation, Characterization and Applications, WileyVCH Verlag GmbH \& Co KGaA, 2015.

[17] J.C. Groen, L.A.A. Peffer, J.A. Moulijn, J. Pérez-Ramírez, Colloids Surfaces A Physicochem. Eng. Asp. $241(2004) 53-58$.

[18] J.C. Groen, J. a. Moulijn, J. Peréz-Ramírez, J. Mater. Chem. 16 (2006) 2121.

[19] D. Verboekend, S. Mitchell, M. Milina, J.C. Groen, J. Pérez-Ramírez, J. Peréz-Ramírez, J. Pérez-Ramírez, J. Phys. Chem. C 115 (2011) 14193-14203.

[20] J. Li, X. Li, G. Zhou, W. Wang, C. Wang, S. Komarneni, Y. Wang, Appl. Catal. A Gen. 470 (2014) 115122.

[21] D.P. Gamliel, H.J. Cho, W. Fan, J.A. Valla, Appl. Catal. A Gen. 522 (2016) 109-119.

[22] T.C. Hoff, D.W. Gardner, R. Thilakaratne, J. Proano-aviles, R.C. Brown, J.P. Tessonnier, Appl. Catal. A Gen. 529 (2017) 68-78.

[23] G. Dai, S. Wang, Q. Zou, S. Huang, Fuel Process. Technol. 179 (2018) 319-323.

[24] Y.-K. Park, H. Ju, H. Su, J. Jeon, J. Kim, R. Ryoo, K. Jeong, "Applied Catal. B, Environ. 95 (2010) 365373. 
[25] H.J. Park, K.H. Park, J.K. Jeon, J. Kim, R. Ryoo, K.E. Jeong, S.H. Park, Y.K. Park, Fuel 97 (2012) 379384.

[26] M. Asadieraghi, W.M.A. Wan Daud, Energy Convers. Manag. 101 (2015) 151-163.

[27] L.Y. Jia, M. Raad, S. Hamieh, J. Toufaily, T. Hamieh, M.M. Bettahar, G. Mauviel, M. Tarrighi, L. Pinard, A. Dufour, Green Chem. 19 (2017) 5442-5459.

[28] L.Y. Jia, M. Raad, S. Hamieh, J. Toufaily, T. Hamieh, M.M. Bettahar, G. Mauviel, M. Tarrighi, L. Pinard, A. Dufour, Green Chem. 19 (2017) 5442-5459.

[29] A. Veses, B. Puértolas, M.S. Callén, T. García, Microporous Mesoporous Mater. 209 (2015) 189-196.

[30] T.C. Hoff, D.W. Gardner, R. Thilakaratne, K. Wang, T.W. Hansen, R.C. Brown, J.P. Tessonnier, (2016) 1473-1482.

[31] P.A. Lazaridis, A.P. Fotopoulos, S.A. Karakoulia, K.S. Triantafyllidis, Front. Chem. 6 (2018) 1-21.

[32] B. Puértolas, A. Veses, S. Calløn, S. Mitchell, T. García, J. Pørez-ramírez, M.S. Callén, J. Pérez-Ramírez, ChemSusChem 8 (2015) 3283-3293.

[33] A. Veses, B. Puértolas, J.M. López, M.S. Callén, B. Solsona, T. García, ACS Sustain. Chem. Eng. 4 (2016) 1653-1660.

[34] A. Saraeian, M.W. Nolte, B.H. Shanks, Renew. Sustain. Energy Rev. 104 (2019) 262-280.

[35] A. Imran, E.A. Bramer, K. Seshan, Biofuel Res. J. 5 (2018) 872-885.

[36] P.M. Mortensen, J.D. Grunwaldt, P.A. Jensen, K.G. Knudsen, A.D. Jensen, Appl. Catal. A Gen. 407 (2011) 1-19.

[37] M. Sharifzadeh, M. Sadeqzadeh, M. Guo, T.N. Borhani, N.V.S.N. Murthy Konda, M.C. Garcia, L. Wang, J. Hallett, N. Shah, Prog. Energy Combust. Sci. 71 (2019) 1-80.

[38] L. Negahdar, A. Gonzalez-Quiroga, D. Otyuskaya, H.E. Toraman, L. Liu, J.T.B.H.B.H. Jastrzebski, K.M. Van Geem, G.B. Marin, J.W. Thybaut, B.M. Weckhuysen, K.M. Van Geem, G.B. Marin, J.W. Thybaut, B.M. Weckhuysen, ACS Sustain. Chem. Eng. 4 (2016) 4974-4985.

[39] A. Jensen, K. Dam-Johansen, M.A. Wójtowicz, M.A. Serio, Energy and Fuels 12 (1998) 929-938.

[40] K. Lazdovica, L. Liepina, V. Kampars, Fuel Process. Technol. 138 (2015) 645-653.

[41] N. Bech, M.B. Larsen, P.A. Jensen, K. Dam-Johansen, Biomass and Bioenergy 33 (2009) 999-1011.

[42] C.E. Greenhalf, D.J. Nowakowski, A.B. Harms, J.O. Titiloye, A. V. Bridgwater, Fuel 108 (2013) 216230 .

[43] T.N. Trinh, P.A. Jensen, D.J. Kim, N.O. Knudsen, H.R. Sørensen, S. Hvilsted, Energy and Fuels 27 (2013) 1399-1409.

[44] M. Auersvald, B. Shumeiko, D. Vrtiška, P. Straka, M. Staš, P. Šimáček, J. Blažek, D. Kubička, Fuel 238 (2019) 98-110.

[45] H. Hernando, A.M. Hernández-Giménez, C. Ochoa-Hernández, P.C.A. Bruijnincx, K. Houben, M. Baldus, P. Pizarro, J.M. Coronado, J. Fermoso, J. Čejka, B.M. Weckhuysen, D.P. Serrano, Green Chem. 20 (2018) 3499-3511.

[46] L.H. Ong, M. Dömök, R. Olindo, A.C. Van Veen, J.A. Lercher, Microporous Mesoporous Mater. 164 (2012) 9-20.

[47] A. Eschenbacher, P.A. Jensen, U.B. Henriksen, J. Ahrenfeldt, C. Li, J.Ø. Duus, U.V. Mentzel, A.D. Jensen, Energy \& Fuels 33 (2019) 397-412.

[48] J.C. Groen, J.A. Moulijn, J. Pérez-Ramírez, Ind. Eng. Chem. Res. 46 (2007) 4193-4201.

[49] O.A. Abdelrahman, K.P. Vinter, L. Ren, D. Xu, R.J. Gorte, M. Tsapatsis, P.J. Dauenhauer, Catal. Sci. Technol. 7 (2017) 3831-3841.

[50] O. Kresnawahjuesa, R.J. Gorte, D. De Oliveira, L.Y. Lau, Catal. Letters 82 (2002) 155-160.

[51] K. Sadowska, K. Góra-Marek, J. Datka, J. Phys. Chem. C 117 (2013) 9237-9244.

[52] N.-L. Michels, (2014).

[53] J.C. Groen, L.A.A. Peffer, J.A. Moulijn, J. Pérez-Ramírez, Microporous Mesoporous Mater. 69 (2004) 29-34.

[54] J. Pérez-Ramírez, S. Mitchell, D. Verboekend, M. Milina, N.-L. Michels, F. Krumeich, N. Marti, M. Erdmann, ChemCatChem 3 (2011) 1731-1734.

[55] W.M. Meier, Nature 289 (1981) 782-783.

[56] E.G. Derouane, S. Detremmerie, Z. Gabelica, N. Blom, Appl. Catal. 1 (1981) 201-224.

[57] J. Li, M. Liu, X. Guo, S. Xu, Y. Wei, Z. Liu, C. Song, ACS Appl. Mater. Interfaces 9 (2017) 2609626106.

[58] J.C. Groen, T. Bach, U. Ziese, A.M. Paulaime-Van Donk, K.P. De Jong, J.A. Moulijn, J. Pérez-Ramírez, J. Am. Chem. Soc. 127 (2005) 10792-10793.

[59] D. Fodor, F. Krumeich, R. Hauert, J.A. Van Bokhoven, Chem. - A Eur. J. 21 (2015) 6272-6277.

[60] A. Oasmaa, D.C. Elliott, J. Korhonen, Energy and Fuels 24 (2010) 6548-6554. 
[61] T.P. Vispute, H. Zhang, A. Sanna, R. Xiao, G.W. Huber, Science 330 (2010) 1222-1227.

[62] A. V. Bridgwater, Biomass and Bioenergy 38 (2012) 68-94.

[63] S. Czernik, A. V. Bridgwater, Energy \& Fuels 18 (2004) 590-598.

[64] R.M. Baldwin, C.J. Feik, Energy and Fuels 27 (2013) 3224-3238.

[65] J. Sitzmann, Upgrading of Fast Pyrolysis Oils by Hot Filtration, 2009.

[66] O. Mante, F.A. Agblevor, S.T. Oyama, R. McClung, Appl. Catal. A Gen. 445-446 (2012) 312-320.

[67] J. Joseph, C. Baker, S. Mukkamala, S.H. Beis, M.C. Wheeler, W.J. DeSisto, B.L. Jensen, B.G. Frederick, Energy \& Fuels 24 (2010) 5153-5162.

[68] M. Xu, C. Mukarakate, K. Iisa, S. Budhi, M. Menart, M. Davidson, D.J. Robichaud, M.R. Nimlos, B.G. Trewyn, R.M. Richards, ACS Sustain. Chem. Eng. 5 (2017) 5477-5484.

[69] S.A. Channiwala, P.P. Parikh, Fuel 81 (2002) 1051-1063.

[70] R.H. Venderbosch, ChemSusChem 8 (2015) 1306-1316.

[71] M.B. Griffin, K. Iisa, H. Wang, A. Dutta, K.A. Orton, R.J. French, D.M. Santosa, N. Wilson, E. Christensen, C. Nash, K.M. Van Allsburg, F.G. Baddour, D.A. Ruddy, E.C.D. Tan, H. Cai, C. Mukarakate, J.A. Schaidle, Energy Environ. Sci. 11 (2018) 2904-2918.

[72] A. Dutta, J.A. Schaidle, D. Humbird, F.G. Baddour, A. Sahir, Top. Catal. 59 (2016) 2-18.

[73] S. Tang, C. Zhang, X. Xue, Z. Pan, D. Wang, R. Zhang, J. Anal. Appl. Pyrolysis (2018).

[74] D. Verboekend, J. Pérez-Ramírez, Chem. - A Eur. J. 17 (2011) 1137-1147.

[75] H.J. Park, H.S. Heo, J.K. Jeon, J. Kim, R. Ryoo, K.E. Jeong, Y.K. Park, Appl. Catal. B Environ. 95 (2010) 365-373.

[76] B.S. Kim, C.S. Jeong, J.M. Kim, S. Bin Park, S.H. Park, J.K. Jeon, S.C. Jung, S.C. Kim, Y.K. Park, Catal. Today 265 (2016) 184-191. 